\title{
Grouprofile: Um Modelo de Gerenciamento de Perfis de Grupos de Aprendizes em Ambiente Virtual de Aprendizagem
}

\author{
Title: Grouprofile: A Profile Management Model of Learning Groups In Virtual Learning \\ Environment
}

\author{
Adalto Selau Sparremberger \\ PPGIE - UFRGS \\ Escola de Engenharia e TI - FADERGS \\ Escola de Tecnologia - FSPOA/SENACRS \\ adaltoss@me.com \\ Aline Zanin \\ PPGCC-PUCRS \\ aline.zanin@acad.pucrs.br
}

\author{
Jorge Luis Victória Barbosa \\ PPGCA - UNISINOS \\ jbarbosa@unisinos.br
}

\author{
João Carlos Gluz \\ IFRS - Campus Canoas \\ jcgluz@gmail.com
}

\begin{abstract}
Resumo
Toda sala de aula, seja ela presencial ou EaD, é caracterizada pela presença física ou virtual de um grupo de aprendizes e professor(es) elou tutor(es). Neste grupo de aprendizes estão pessoas com os mais diversos perfis, e uma das missões do educador que está conduzindo a turma, é identificar este perfil de cada estudante e do grupo. Através desta identificação de perfil, o educador pode adequar as suas estratégias de ensino, dando um suporte maior para os alunos que possuem maior dificuldade e valorizando as aptidões de cada aluno. Por exemplo: se o aluno se destaca por sua proatividade, esta característica deve ser explorada. Desta forma, utilizar mecanismos que suportem esta identificação de perfil podem auxiliar os professores neste processo. Considerando que é comum nos cursos presenciais e principalmente nos cursos EaD fazer uso de ambientes virtuais de ensino, para apoiar parcial ou totalmente as atividades propostas para a turma, é proposto neste trabalho a utilização de um modelo que coleta informações destes ambientes e mapeia para o professor o perfil do grupo de aprendizes em relação a: aprendizes com maior e menor desempenho; aprendizes com maior e menor proatividade, reatividade e interesse.
\end{abstract}

Palavras-chave: rouprofile, identificação de perfil, identificação de perfil de grupo

\begin{abstract}
Every classroom, whether face-to-face or EaD is characterized by the physical or virtual presence of a group of learners and a teacher or tutor. In this group of learners are people with the most diverse profiles, and one of the missions of the educator who is leading the class is to identify this profile of each student and the group. With this profile identification, it is possible for the educator adapt their teaching strategies giving greater attention to students who have more difficulties and valuing the aptitudes of each student. For example: if the student stands out for his proactivity, this characteristic must be explored. In this way, using mechanisms that support this profile identification can help teachers in this process. Considering that it is common in the classroom courses and especially in the EaD courses to make use of virtual environments of teaching, to support partially or totally the activities proposed for the class, we propose in this work the use of a model that collects information of these environments and maps to the
\end{abstract}

Cite as: Sparremberber, A. S., Barbosa, J. L. V., Gluz, J. C., Zanin, A. \& Becker, T. P. (2019). Grouprofile: A Profile Management Model of Learning Groups In Virtual Learning Environment (Grouprofile: Um Modelo de Gerenciamento de Perfis de Grupos de Aprendizes em Ambiente Virtual de Aprendizagem). Brazilian Journal of Computers in Education (Revista Brasileira de Informática na Educação - RBIE), 27(3), 369-402. DOI: 10.5753/RBIE.2019.27.03.369. 
teacher the profile of the group of learners in relation to: learners with higher and lower performance; learners with greater and lesser proactivity, reactivity and interest.

Keywords: rouprofile, profile identification, group profile identification

\section{Introdução}

Ambientes Virtuais de Aprendizagem (AVA) são ferramentas tecnológicas que foram criadas para apoiar o ensino e a aprendizagem (Penterich, 2005). Estas ferramentas são mais conhecidas por sua utilização em cursos oferecidos na modalidade $\mathrm{EaD}$, uma vez que, nesta modalidade os cursos dependem dos AVAs para viabilizar a sua execução. Entretanto, estas ferramentas podem e devem ser utilizadas também em cursos presenciais, conforme prevê a organização dos modelos de Ensino Híbrido (Horn, Staker, \& Christensen, 2015), que aborda formas de encaminhamento das aulas em que as tecnologias digitais podem ser inseridas de forma integrada ao currículo e adquirir com isso um papel essencial no processo de ensino. Essas tecnologias destacam-se por exemplo por permitirem ao docente diversas possibilidades, dentre elas: a armazenagem de materiais, realização de avaliações, recebimento de trabalhos dos alunos, acompanhamento do desempenho dos alunos no que se refere a diversos indicadores, entre eles: as notas, a proatividade, a reatividade e o interesse do estudante frente às propostas, neste caso, mediadas pelo professor.

O perfil individual dos estudantes e o perfil da turma baseado nos índices supracitados é mais facilmente obtido em cursos ofertados na modalidade presencial, uma vez que, estes cursos se beneficiam da interação diária e presencial com o aluno, propiciando ao docente identificar no comportamento do aluno em sala de aula, situações que caracterizem proatividade, reatividade e interesse acima da média da turma, bem como, comportamentos que caracterizem índices abaixo da média da turma. De posse destes dados o docente pode optar por personalizar as suas aulas de acordo com o perfil da turma ou personalizar materiais por aluno para valorizar suas características positivas principais.

Considerando que proatividade é o comportamento relacionado ao ato de praticar ações concretas por iniciativa pessoal para aprimorar o processo ensino-aprendizagem (Aretio, Corbella, \& Figaredo, 2007). Por outro lado, uma pessoa que tem como característica ser apenas reativa, irá aguardar que o professor disponibilize os materiais a ela (Primo, 1998).

A proatividade e a reatividade em conjunto com o interesse, são fatores que ao considerar o modelo de desenvolvimento de Competências CHA (conhecimentos, habilidades e atitudes) (Fleury \& Fleury, 2001), estão classificados no âmbito das atitudes e desta forma contribuem com a avaliação do desesempenho do estudante.

Desta forma, visando proporcionar ao professor de cursos ofertados na modalidade EaD, a mesma possibilidade de identificar o perfil comportamental dos alunos de cursos presenciais, os AVAs precisam estar constantemente sendo atualizados, revistos e incrementados. Nesse sentido, 
e para que o professor possa fazer uma leitura do grupo de aprendizes, com maior precisão, se faz necessário que sejam estabelecidas métricas. O modelo Grouprofile, proposto por Sparremberger, Barbosa, and Gluz (2017) apresenta métricas para mensurar proatividade, reatividade, interesse e desempenho de grupos de aprendizes em ambientes virtuais de aprendizagem.

Entretanto, analisando os dois contextos de modalidades de ensino (presencial e EaD), identificou-se a necessidade de detalhar as métricas propostas pelo Grouprofile, para que o modelo possa ser aplicado tanto na educação a distância, quanto no ensino presencial.

Neste contexto, embasa-se este trabalho na hipótese de pesquisa que: desenvolver um modelo que apresente ao professor os alunos com maior e menor desempenho nos critérios de proatividade, reatividade, interesse e desempenho geral auxilia o professor no planejamento de aulas e no acompanhamento dos alunos.

Aliado a esta hipótese consideramos como questões de pesquisa principais: como medir proatividade, reatividade e interesse dos aprendizes e quais critérios utilizar para a medição de desempenho dos aprendizes.

Visando confirmar a hipótese supracitada e responder as questões de pesquisa estabelecidas, este trabalho está organizado da seguinte forma: primeiramente, na Seção 2 apresentam-se os trabalhos relacionados e discute-se as contribuições apresentadas pelo Grouprofile em relação aos demais trabalhos. Posteriormente, na Seção 3 apresenta-se a fundamentação teórica dos principais temas que se fazem necessários para compreensão deste trabalho. Na Seção 4 apresentam-se as etapas de pesquisa percorridas para a definição do modelo Grouprofile e para sua readequação. Na Seção 5 apresenta-se o modelo Grouprofile e por fim, na Seção 7 apresenta-se a avaliação do modelo e a discussão dos resultados identificados.

Esse trabalho amplia o texto publicado no SBIE 2017 (Sparremberger et al., 2017) através dos seguintes principais conteúdos: (1) os componentes da arquitetura proposta foram detalhados na Seção 5, principalmente através de uma descrição completa dos agentes; (2) a discussão sobre as métricas aplicadas no modelo foi aprofundada na Seção 5.6; (3) uma descrição mais detalhada do protótipo é apresentada na Seção 6; (5) finalmente, a validação da proposta foi discutida de forma mais completa na Seção 7.

\section{Trabalhos Relacionados}

O objetivo desta etapa foi identificar trabalhos realizados por outros pesquisadores, que apresentam contribuições no mesmo ponto focal deste estudo. Neste sentido destaca-se os seguintes trabalhos:

- O trabalho "UbiGroup - Um Modelo de Recomendação Ubíqua de Conteúdo para Grupos de Aprendizes", este trabalho tem como objetivo desenvolver um método de recomendação ubíqua de objetos de aprendizagem para grupos de aprendizes que possuem o mesmo 
contexto. Este trabalho relaciona-se com o modelo Grouprofile porque ambos trabalham no contexto de perfil de aprendizes, contudo, o UbiGroup tem foco em recomendação de materiais e não em identificação de proatividade, reatividade e interesse (Ferreira, Barbosa, Gluz, \& Vicari, 2015).

- Este trabalho foi posteriormente estendido no trabalho denominado EduTrail, Um Modelo para Gerenciamento de Perfis de Entidades Através de Inferência em Trilhas. Este modelo permite o acompanhamento ubíquo de grupos de aprendizes realizando um registro histórico dos contextos, a partir de informações provenientes dos temas e tópicos do plano de ensino, dos perfis individuais e de grupos de alunos. Este trabalho também se assemelha ao modelo Grouprofile por apresentar mapeamento de perfil de grupos de aprendizes, contudo, ele não considera proatividade, reatividade e interesse (Nóbrega, Barbosa, \& Barbosa, 2015).

- O trabalho: PeLeP - Pervasive Learning Profile que tem por objetivo possibilitar que as aplicações educacionais possam explorar o ensino e aprendizagem ubíquos, baseando-se em um perfil organizado por categorias que contêm informações da vida cotidiana do aprendiz. Este trabalho considera as informações da vida cotidiana do aprendiz, não levando em consideração a interação com ambiente virtual de aprendizagem, proatividade, reatividade e interesse (Levis, Barbosa, Pinto, \& Barbosa, 2008).

- O trabalho “Análise Visual para Monitoramento de Alunos de Cursos a Distância”, propõe através de algoritmos de visualização de dados, melhorar o acesso do docente a informações referentes aos alunos dos cursos EaD. Este trabalho se difere do Grouprofile porque não propõe métricas específicas para análise de proatividade, reatividade, interesse e explora a visualização dos dados sem considerar ranqueamento dos alunos (Weiand et al., 2016).

- Em outro trabalho foi apresentado um plugin para o AVA Moodle chamado Analytics Graphs. Este plugin permite ao professor visualizar o perfil dos alunos de acordo com notas, acesso a arquivos, recursos e envio de tarefas. Contudo, nesta ferramenta estes quesitos são avaliados de forma individual não sendo utilizados para a medição de proatividade, reatividade e interesse (Schmitt, Tarouco, Okuyama, Zielinski, \& Franco, 2015).

O modelo Grouprofile se relaciona com os trabalhos supracitados uma vez que, de alguma forma todos os trabalhos consideram perfis de aprendizes ou de grupos de aprendizes. Contudo, conforme descrito na análise individual de cada trabalho, nenhum dos trabalhos localizados durante a pesquisa, apresenta métricas para cálculo de proatividade, reatividade e interesse. A principal contribuição do modelo Grouprofile é exatamente a definição destas métricas tanto para a modalidade de cursos presenciais quanto para modalidade de cursos EAD. Além disso, o modelo Grouprofile avança o estado da arte propondo um índice para avaliação de desempenho dos estudantes que considera estas variáveis e a nota das atividades. 


\section{Fundamentação Teórica}

O modelo Grouprofile, baseia-se na utilização de ambientes virtuais de aprendizado e do mapeamento do comportamento dos aprendizes nestes ambientes. Um ambiente virtual de aprendizagem consiste em uma opção de mídia que está sendo utilizada para mediar o processo de ensino-aprendizagem a distância (Pereira, Schmitt, \& Dias, 2007). Em outras palavras, um AVA é todo aquele ambiente que é utilizado para suportar a aprendizagem de forma virtual. Existem vários exemplos de AVA, sendo um dos mais conhecidos e que é utilizado para os testes do modelo Grouprofile o AVA Moodle (Modular Object Oriented Distance Learning) (Moodle, 2019).

Os ambientes virtuais de aprendizagem são utilizados pelos alunos para diversas ações, por exemplo: realização de atividades, acesso aos conteúdos disponibilizados pelo professor, interação com colegas e realização de atividades avaliativas. A partir do comportamento do aprendiz nestes ambientes é possível notar suas características no que diz respeito a proatividade, reatividade e interesse.

Ações proativas são aquelas nas quais o indivíduo age por iniciativa própria, sem incentivo ou influência de ações de terceiros. Ações reativas, por sua vez, referem-se a ações que são tomadas como resposta a um estímulo (Amaral, Ávila, Zednik, \& Tarouco, 2011). O interesse une os dois conceitos, sendo que: um indivíduo interessado é aquele que tem enfoque em algum determinado objetivo e toma ações para atingi-lo. Com relação a estas e outras características pode se estabelecer perfis de usuários (no contexto deste trabalho aprendizes) e perfis de grupo de usuários.

O perfil de um usuário pode ser caracterizado como um conjunto de informações relevantes a seu respeito, processado a partir de suas decisões (Wagner, Barbosa, \& Barbosa, 2014). Já o perfil de grupo diz respeito a sumarização dos perfis dos usuários que compoem o grupo, categorizandoos e montando um perfil que represente o grupo de acordo com as categorias estabelecidas, por exemplo: perfil do grupo em relação a proatividade.

Para realizar a análise de perfil de grupo de forma automatizada diversos tipos de sistemas computadorizados podem ser utilizados. Um exemplo de tipo de sistema que pode ser utilizado é um sistema multiagente.

Um agente representa um componente de software que possui inteligência e autonomia, que é utilizado para auxiliar o usuário na realização de alguma tarefa ou atividade (Wooldridge, 2009). Um agente é uma entidade autônoma que pode interagir e adaptar-se com o próprio ambiente (Russell \& Norvig, 1995). O fato de um agente ser autônomo, significa que ele possui uma existência própria, podendo trabalhar sem interação com o usuário ou outros agentes.

Quando um sistema computacional possui mais de um agente, coordenados entre si através de suas relações, temos então um sistema multiagente (Odell, 2010). Em um sistema multiagente, cada agente controla uma thread (processo). Este é o caso do sistema desenvolvido para suportar o modelo proposto neste trabalho. 


\section{Desenho de Pesquisa}

Nesta Seção apresenta-se o detalhamento das etapas realizadas no desse trabalho. É apresentada a descrição das seguintes etapas: Análise dos Trabalhos Relacionados; Definição do conceito de Proatividade, Reatividade e Interesse; Definição do Modelo Grouprofile; Implementação da Ferramenta Grouprofile; Aplicação do Modelo Grouprofile em um dos grupos de aprendizes e Comparação da Percepção do Professor com o Demonstrado Pela Ferramenta. Estas etapas sã sintetizadas na Figura 1

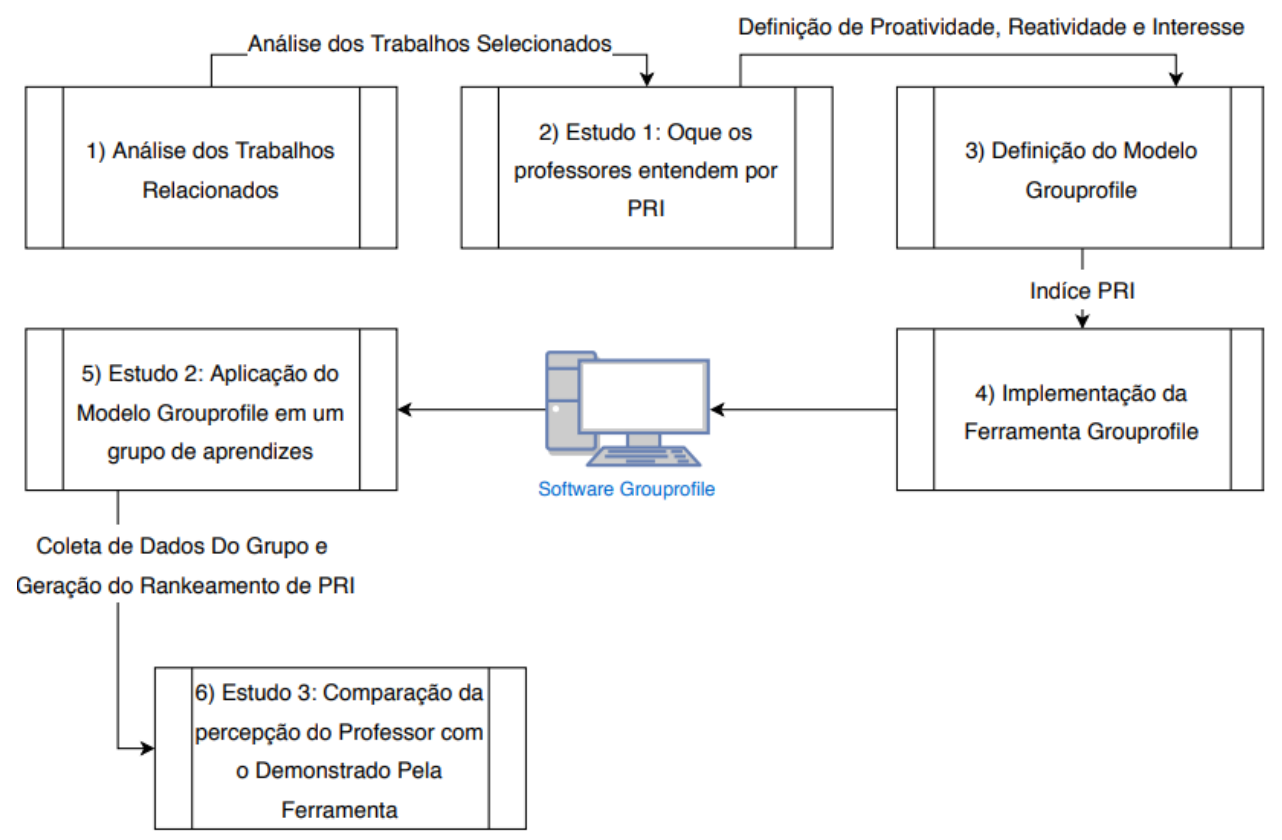

Figura 1: Desenho de Pesquisa.

1. Análise dos Trabalhos Relacionados: nesta etapa buscou-se localizar os trabalhos que se relacionam com o apresentado neste estudo. Inicialmente analisou-se os trabalhos previamente publicados pelo grupo de pesquisa onde este trabalho foi inicialmente concebido e posteriormente analisaram-se as referências e citações destes trabalhos. Os trabalhos que se relacionam mais diretamente com o Grouprofile foram descritos na Seção 2. Com a análise destes trabalhos identificou-se a inexistência de trabalhos que efetuam a classificação dos grupos de aprendizes em relação a proatividade, reatividade e interesse.

2. Definição do conceito de Proatividade, Reatividade e Interesse: Nesta etapa efetuou-se um survey em formato de questionário que teve por objetivo identificar como os professores costumam caracterizar proatividade, reatividade e interesse em seus alunos, bem como entender como estes critérios afetam a avaliação de desempenho do aluno. O resultado desta pesquisa bem como o detalhamento da mesma está descrito na Seção 5.5. 
3. Definição do Modelo Grouprofile: com base nas métricas descritas pelos professores, foi concebido o modelo PRI, que estipula pesos e medidas para proatividade, reatividade e interesse no cálculo de desempenho geral, bem como estipula critérios para avaliação da proatividade, reatividade e interesse. O modelo Grouprofile é detalhado na Seção 5.

4. Implementação da Ferramenta Grouprofile: Nesta etapa efetuou-se a representação do Modelo Grouprofile em um software. Este software faz a leitura dos dados da interação dos aprendizes com o AVA Moodle e efetua a apresentação dos dados para o professor. O software Grouprofile atua neste contexto como um monitor, os dados são lidos pela ferramenta e o ranqueamento e pontuação dos alunos constantemente atualizados. Mais detalhes sobre a implementação podem ser vistos na Seção 6.

5. Estudo 2: Aplicação do Modelo Grouprofile em um dos grupos de aprendizes: depois de concluído o desenvolvimento software, integrou-se o Grouprofile com o AVA Moodle, o qual dois grupos de alunos, sendo um EaD e um presencial, estavam utilizando. A partir disto, o software efetuou a análise destes e o ranqueamento dos alunos. Os dados desta etapa de pesquisa são apresentados em detalhes da Seção 7.

6. Estudo 3: Comparação da Percepção do Professor com o Demonstrado Pela Ferramenta: para garantir a validade das métricas que formam o modelo PRI, perguntou-se ao professor titular da turma, qual a percepção dele em relação aos alunos com maior e menor proatividade, reatividade, interesse e desempenho geral e posteriormente, comparou-se a percepção do professor com o apontado pelo modelo Grouprofile. Os dados desta pesquisa são apresentados em detalhes da Seção 7.

\section{Modelo Grouprofile}

Grouprofile (Sparremberger et al., 2017), é um modelo que cria, mantém e registra o histórico do perfil de consenso de grupos de aprendizes. Este perfil de consenso é baseado em proatividade, reatividade e interesse do grupo, sendo que, estes critérios são avaliados conforme métricas predefinidas por este modelo.

Para suportar o trabalho de cálculo e apresentação de resultados baseados nas métricas que o modelo estabelece, o Grouprofile é formado por quatro agentes. Estes agentes se comunicam com a base de dados do Grouprofile e com a base de dados do AVA fazendo uma mineração de dados educacionais. Nesta mineração de dados, as informações sobre o comportamento dos aprendizes no AVA são mineradas do banco de dados do AVA para o banco de dados do Grouprofile, e a partir dela, o Grouprofile aplica as métricas retornando ao professor informações sobre o perfil de consenso do grupo.

Os agentes utilizados pelo Grouprofile são os seguintes: 
1. Agente Apoio Docente: provê acesso ou Grouprofile utilizando as credenciais do AVA e retorna o contexto do grupo (presencial ou EaD);

2. Agente Gestor de Contextos: define as métricas para cada contexto;

3. Agente Gestor de Perfis de Grupos: gera os perfis dos grupos de acordo com o contexto informado pelo Agente Gestor de Contextos, considerando proatividade, reatividade, interesse e desempenho;

4. Agente Registra Histórico: é o responsável por armazenar o histórico do grupo de aprendizes.

É importante enfatizar que estes agentes são agentes reativos, uma vez que,eles reagem às alterações da base de dados, atualizando para o professor o perfil do grupo. Contudo, eles não possuem inteligência artificial acoplada. A Figura 2 mostra a representação do modelo Grouprofile que é composto de quatro agentes de software.



Figura 2: Modelo Grouprofile.

\subsection{Agente Apoio Docente (AD)}

O Agente Apoio Docente é inspirado no Agente Apoio Pedagógico, que integra o modelo Ubigroup. Este agente é responsável pela interface com o docente. O AD é utilizado primeiramente para efetuar a autenticação do usuário no Grouprofile. Para este fim, as credenciais do docente são buscadas no banco de dados do AVA, ou seja, o Grouprofile e o AVA utilizam os mesmos dados para login. Uma vez logado, o AD acessará o Agente Gestor de Contextos para informar o contexto no qual o usuário logado esta inserido. Neste trabalho, contexto se refere a modalidade de ensino, EaD ou presencial. 


\subsection{Agente Gestor de Contextos (GC)}

O Agente Gestor de Contextos é o agente responsável por receber e confirmar a informação referente a modalidade de ensino e atribuir as métricas utilizadas pelo modelo Grouprofile para cada modalidade.

\subsection{Agente Gestor de Perfis de Grupos (GPG)}

O Agente Gestor de Perfis de Grupos (GPG) tem a responsabilidade de se comunicar com os agentes Gestor de Contextos e Registro Histórico, com o propósito de monitorar os grupos de aprendizes, baseando-se em análise dos históricos de contextos dos grupos (Dey, Abowd, \& Salber, 2001) (Silva, Rosa, Barbosa, Barbosa, \& Palazzo, 2009). O objetivo destas ações, é permitir ao professor que gerencie e receba notificações de movimentações de determinado grupo, através de um monitor de grupos. A cada movimentação e/ou evolução do grupo, seu novo perfil será gerado de forma dinâmica e armazenado, criando assim um histórico de evolução do grupo. A Figura 3 apresenta a modelagem do agente Gestor de Perfis de Grupos, com as capacidades de Registrar alterações dos perfis dos grupos de aprendizes, conforme representa o diagrama de capacidades na Figura 4(a) e exibir as alterações dos perfis dos grupos de aprendizes, de acordo com a representação do diagrama de capacidades contido na Figura 4(b).

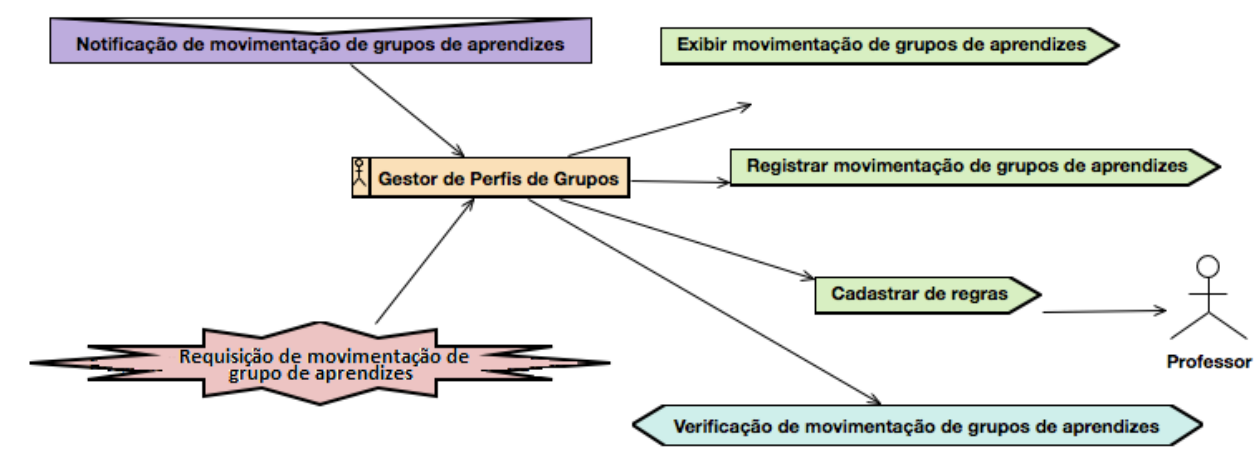

Figura 3: Agente Gestor de Perfis de Grupos de Aprendizes.

Os perfis são compostos dos seguintes campos: proatividade, reatividade, interesse, quartil de aprendizes com melhor desempenho, quartil de pior desempenho e modalidade do curso. $\mathrm{O}$ agente GPG realiza uma requisição de notificações de alterações nos perfis dos grupos de aprendizes no contexto. A partir desta requisição, toda vez que o agente identificar o evento requisitado, ele registra o novo perfil do grupo.

O trabalho conjunto de todos os agentes supracitados é responsável pela criação, manutenção e registro histórico do perfil de consenso de grupos de aprendizes. Para formulação deste perfil de consenso são utilizadas algumas métricas, sendo elas descritas a seguir. 


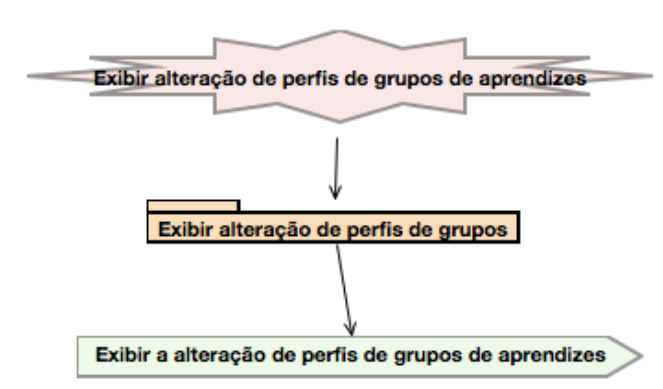

(a) Capacidade do Agente Gestor de Perfis de Grupos de exibir alterações

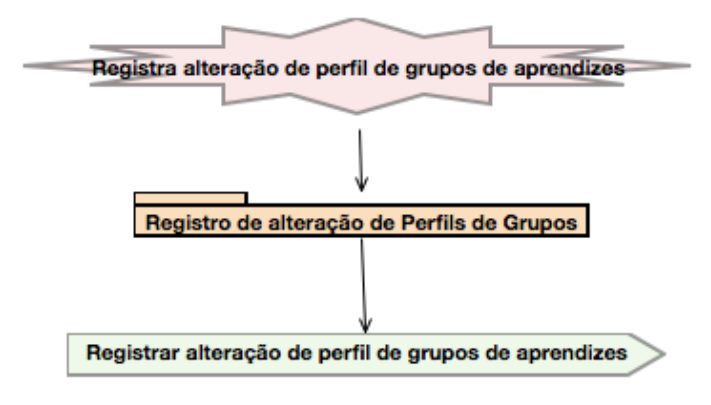

(b) Capacidade do Agente Gestor de Perfis de Grupos de registrar alterações

Figura 4: Capacidades Agente Gestor de Perfis de Grupos de Aprendizes.

\subsection{Agente Registro Histórico (RH)}

Inspirado no modelo EduTrail, o Agente Registro Histórico tem por sua responsabilidade o registro dos históricos dos contextos dos grupos de aprendizes, a partir das informações mantidas pelo agente Gestor de Contextos (GC).

É sua função registrar as seguintes informações do grupo de aprendizes referentes as atividades: data, modalidade do curso, valores que compõem os indicadores de proatividade, reatividade e interesse, quartis de aprendizes com melhor e pior desempenho. Na Figura 5 é apresentado o diagrama do agente $\mathrm{RH}$.

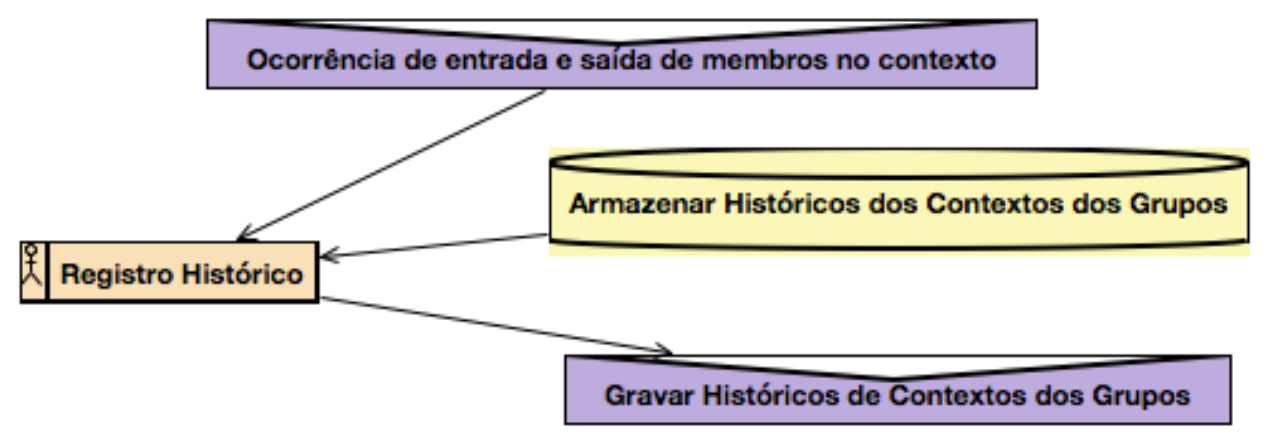

Figura 5: Agente Registro de Histórico.

\subsection{Definição do conceito de Proatividade, Reatividade e Interesse}

Grouprofile é um framework que cria, mantêm e registra histórico do perfil de consenso de grupos de aprendizes. Este perfil de consenso é baseado em proatividade, reatividade e interesse do grupo, sendo que, estes critérios são avaliados conforme métricas predefinidas pelo modelo Grouprofile. 
Para concepção deste modelo, primeiramente buscou-se identificar junto a um grupo formado por trinta e seis professores, todos professores de cursos técnicos ou de nível superior, quais os critérios que estes costumam utilizar para classificação de proatividade, reatividade e interesse entre os grupos de aprendizes dos quais são professores. Para isso realizou-se um survey, em formato de questionário. Optou-se por utilizar questionário, por este método permitir que o pesquisador receba dados de respondentes que não estão no mesmo espaço físico que o pesquisador, bem como por permitir flexibilidade de horário e privacidade nas respostas.

O questionário foi elaborado levando em consideração dados preliminares coletados em um brainstorm realizado junto aos colegas professores da instituição em que a maioria dos pesquisadores responsáveis pelo trabalho atuam. Este brainstorm foi realizado de forma informal e teve o intuito apenas de fornecer informações para estruturação do questionário. Um piloto do questionário foi executado junto a dois professores, para validar a estrutura do questionário. As perguntas efetuadas, bem como as alternativas dadas para cada uma delas, foram as seguintes:

Questão 01: Quais das seguintes opções caracterizam proatividade de alunos, na sua opinião, tendo como opções: Número de acessos ao ambiente virtual de ensino; Periodicidade de acessos; Acessos ao ambiente virtual efetuados fora do período de provas e trabalhos; Entrega de trabalhos de forma antecipada; Entrega de trabalhos no prazo estabelecido; Número de interações no ambiente virtual (resposta a perguntas, posts efetuados...); Perfil completo no ambiente virtual (foto perfil, nome completo, telefone, perfil rede social ), e; outros. As respostas obtidas foram as seguintes:

[label=)]Número de interações no ambiente virtual: 75\%. Acessos ao ambiente virtual efetuados fora do período de provas e trabalhos: 55,6\%; Entrega de trabalhos no prazo estabelecido: 38,9\%; Periodicidade de acessos: 38,9\%; Entrega de trabalhos de forma antecipada: 33,3\%; Número de acessos ao ambiente virtual de ensino: 19,4\%.

Por tratar de uma questão de múltipla-escolha os percentuais não são somatórios, eles representam o número de respostas dadas entre os respondentes para cada uma das alternativas.

Questão 2: Quais das seguintes opções caracterizam reatividade de alunos em ambientes virtuais, na sua opinião, tendo como opções de resposta: Número de comentários em postagens de colegas (Fórum de Discussões); Número de comentários em dúvidas postadas por colegas no fórum de dúvidas; Percentual de respostas de atividades; Respostas de E-mails, e; outros. As respostas obtidas foram as seguintes:

[label=)]Número de comentários em postagens de colegas (Fórum de Discussões): 74,3\%; Número de comentários em dúvidas postadas por colegas no fórum de dúvidas: 54,3\%; Percentual de respostas de atividades: 40\%; Respostas de E-mails: $28 \%$.

Questão 3: Quais das seguintes opções caracterizam interesse de alunos em ambientes virtuais, na sua opinião, tendo como alternativas de respostas: Entrega de todos trabalhos e no prazo; Número de interações no ambiente virtual maior que a média de todos acessos da turma; 
Número de dúvidas enviadas ao professor; Número de acessos a materiais extra, e; outros. As respostas obtidas foram as seguintes:

[label=)]Entrega de todos trabalhos e no prazo: 44,4\%; Número de interações no ambiente virtual maior que a média de todos acessos da turma: $61,1 \%$; Número de dúvidas enviadas ao professor: $30,6 \%$; Número de acessos a materiais extra: $55,6 \%$.

Questão 4: Como você classificaria o grupo de alunos com maior desempenho, tendo como alternativas: Pelo índice de proatividade, reatividade, interesse e pelas notas; Apenas pelas notas; Apenas pela proatividade e interesse; Tendo proatividade e interesse peso superior a nota, e; Tendo nota pelo superior a proatividade e interesse. As respostas obtidas foram as seguintes:

[label=)]Pelo índice de proatividade, reatividade, interesse e pelas notas: $80 \%$; Apenas pelas notas: 2,8\%; Apenas pela proatividade e interesse: $8,3 \%$; Proatividade e interesse com peso superior a nota: $33,3 \%$; Nota com peso superior a proatividade e interesse: $22,2 \%$.

\subsection{Definição das métricas que compõem o modelo Grouprofile}

Baseado no resultado do Survey que foi descrito na seção anterior, foram elaboradas as métricas que são utilizadas para medição de proatividade, reatividade e interesse. A seguir, a análise de cada um destes critérios.

\subsubsection{Definição de Proatividade}

Uma interação proativa segundo (Amaral et al., 2011), ocorre quando o aluno vai além do proposto pelo docente, selecionado ou respondendo as estruturas existentes, construindo assim situações únicas e elaborações que forçam os limites do sistema.

Para a definição das métricas de proatividade nos baseamos na questão de número 1(um) do questionário, e visto que, a alternativa "Número de interações no ambiente virtual" foi a melhor pontuada, elaborou-se as métricas apresentadas a seguir.

5. Definição de Proatividade em Cursos EaD

- Número de interações no ambiente virtual: 3 pontos.

- Para se obter a média de interação de cada aprendiz no ambiente virtual, é realizado um comparativo do número de interações por ele efetuadas (IA) com o número de interações efetuadas pelo aprendiz que realizou o maior número de interações neste grupo (MI), e aplicada a Equação 1.

$$
\text { Proatividade }=\frac{I A}{M I} * 3
$$


- Periodicidade de acessos ao ambiente virtual: 3 pontos.

- Alunos que efetuam acesso apenas em período de até 24 horas antes de entregas de tarefas contabilizam 1 ponto.

- Alunos que acessam o ambiente continuamente, 2 pontos.

- Alunos que acessam continuamente e no período de até 24 horas após o professor ter lançado uma tarefa, 3 pontos.

- Entrega de trabalhos: 3 pontos.

- Alunos que efetuam entregas das tarefas no período das primeiras 24 horas prazo, 3 pontos.

- Alunos que efetuam entregas na primeira metade do prazo, 2 pontos.

- Alunos que efetuam entregas na segunda metade do prazo, 1 ponto.

- Número de acessos: 0,5 pontos.

- Alunos com número de acesso superior a média, 0,5 ponto.

- Cadastro Completo: 0,5 pontos.

- Alunos com cadastro completo, considerando-se nome, sobrenome, telefone, cidade e foto, sendo atribuídos 0,1 pontos para cada um destes itens.

2. Métrica de Proatividade em Cursos Presenciais

Para alunos de cursos presenciais, a métrica aplicada para proatividade sofre uma alteração, uma vez que, em cursos presenciais o uso do fórum não tem uma importância tão significativa quanto em cursos $\mathrm{EaD}$, aonde este recurso passa a ser um dos principais ou por vezes o principal recurso de comunicação. Desta forma consideramos o seguinte:

- Periodicidade de acessos ao ambiente virtual: 4 pontos.

- Acessos apenas em período de até 24 horas antes de entregas de tarefas contabilizam: 1 ponto.

- Acessos ao ambiente de forma contínua: 3 pontos.

- Acessos ao ambiente de forma contínua e no período de até 24 horas após o professor ter lançado uma tarefa: 4 pontos.

- Entrega de trabalhos: 4 pontos.

- Alunos que efetuam entregas das tarefas no período das primeiras 24 horas prazo, 4 pontos.

- Alunos que efetuam entregas na primeira metade do prazo, 3 pontos.

- Alunos que efetuam entregas na segunda metade do prazo, 2 pontos.

- Alunos que efetuam entregas no ultimo dia, 1 ponto.

Para cada avaliação é somada a pontuação referente ao período em que foi entregue e a soma total de todas as avaliações é dividida pelo número de avaliações. 
- Número de interações no ambiente virtual: 1 ponto.

- Para o aluno com número de acessos acima da média do grupo.

- Número de acessos: 0,5 pontos

- Alunos com número de acesso superior a média, 0,5 pontos.

- Cadastro Completo: 0,5 pontos.

- Alunos com cadastro completo, 0,5 pontos.

\subsubsection{Definição de Reatividade}

Conforme (Amaral et al., 2011), uma interação reativa é a resposta ao estímulo do sistema sobre o usuário, ou resposta para a questão colocada. $\mathrm{O}$ material disponibilizado pelo professor, guia o aluno através de um fluxo pré-determinado.

Para a definição das métricas de reatividade, nos baseamos na resposta na segunda questão do questionário, devido ao fato de, número de comentários em postagens de colegas e percentual de respostas de atividades, serem os itens mais pontuados, definiu-se as seguintes métricas.

1. Métrica de Reatividade em Ambiente EaD

As métricas estabelecidas para mensurar a reatividade em ambientes EAD foram as seguintes:

- Entrega de trabalhos e atividades: 2 pontos

- Cálculo proporcional ao total de trabalhos e atividades entregues no prazo, sendo efetuado da seguinte maneira: total de entregas efetuadas no prazo (EP), divididas pelo total de atividades solicitas (AS) e multiplicado por dois, conforme a Equação 2:

$$
\text { Entregas }=\frac{E P}{A S} * 2
$$

- Envio de e-mail: 2 pontos:

- Acima da média do grupo: 2 pontos;

- Acima da metade média do grupo: 1 ponto;

- Maior que zero e até a metade da média do grupo: 0,5 pontos.

- Número de acessos: 1 ponto:

- Acima da média do grupo: 1 ponto;

- Maior que zero e até a média do grupo: 0,5 pontos.

- Número de Interações: 3 pontos

- Acima da média do grupo: 3 pontos; 
- Acima da metade da média do grupo: 2 pontos;

- Maior que zero e até a metade da média do grupo: 1 ponto.

- Postagem em chat: 2 pontos:

- Acima da média do grupo: 2 pontos;

- Acima da metade da média do grupo: 1 pontos;

- Maior que zero e até a metade da média do grupo: 0,5 ponto.

2. Métrica de Reatividade em Ambiente Presencial

As métricas estabelecidas para mensurar a reatividade em ambientes presenciais foram as seguintes:

- Entrega de trabalhos e atividades: 4 pontos

- Cálculo proporcional ao total de trabalhos e atividades entregues no prazo, sendo efetuado da seguinte maneira: total de entregas efetuadas no prazo (EP), divididas pelo total de atividades solicitas(AS) e multiplicado por dois, de acordo com a Equação 3.

$$
\text { Entregas }=\frac{E P}{A S} * 4
$$

- Envio de e-mail: 2 pontos:

- Acima da média do grupo: 2 pontos;

- Acima da metade média do grupo: 1 ponto;

- Maior que zero e até a metade da média do grupo: 0,5 pontos.

- Número de acessos ao ambiente virtual: 2 pontos:

- Acima da média do grupo: 2 pontos;

- Acima da metade média do grupo: 1 ponto;

- Maior que zero e até a média do grupo: 0,5 pontos;

- Número de comentários em fórum: 1 ponto

- Acima da média do grupo: 1 ponto;

- Maior que zero e até a média do grupo: 0.5 pontos;

- Postagem em chat: 1 pontos:

- Acima da média do grupo: 1 pontos;

- Maior que zero e até a média do grupo: 0,5 pontos. 


\subsubsection{Definição de Interesse}

Para a definição das métricas de interesse, nos baseamos na resposta da terceira pergunta do questionário. Neste caso as alternativas que foram avaliadas como características de interesse pelos profissionais que responderam o questionário foram: "Número de interações no ambiente virtual maior que a média de todos acessos da turma" e "Número de acessos a materiais extras". Desta forma a métrica estabelecida valoriza mais estes critérios, sendo ela a seguinte:

- Número de interações no ambiente virtual maior que a média de todos acessos da turma: 3 pontos;

- Número de dúvidas enviadas ao professor maior do que a média da turma: 1 ponto;

- Número de acessos a materiais extra maior do que a média da turma - 3 pontos;

- Entrega de trabalhos e atividades: 3 pontos, sendo:

- Alunos que efetuam entregas na primeira metade do prazo: 3 pontos;

- Alunos que efetuam entregas na segunda metade do prazo: 2 pontos;

- Alunos que atrasam entregas de trabalhos, não pontuam.

Para a avaliação de interesse a métrica não foi alterada de cursos presenciais para o cursos EAD, uma vez que, os fatores associados a o índice de interesse (interações no ambiente virtual, dúvidas enviadas ao professor, acessos a materiais extra e Entrega de trabalhos e atividades) tem a mesma relevância nos dois ambientes, uma vez que, um aluno que frequenta as aulas presencialmente e além disso utiliza o suporte do ambiente virtual demonstra uma maior interesse de acordo com a percepção dos professor.

\subsubsection{Definição de alunos com maior desempenho e alunos com menor desempenho}

A métrica que mensura alunos com maior e menor desempenho foi criada baseada na pergunta de número quatro do questionário, para qual $80 \%$ dos respondentes consideraram que o desempenho dos alunos deve ser medido"Pelo índice de proatividade, reatividade, interesse e pelas notas".

Desta forma, estes quatro critérios foram considerados para formulação da métrica de ranqueamento dos alunos de acordo com desempenho. A Equação 4 apresenta o índice PRI, que foi desenvolvido para reunir os 3 critérios avaliados (proatividade, reatividade e interesse). Neste índice, reatividade e interesse possuem igual peso, ao passo que proatividade possui um peso maior, dado que, entendemos que um aluno proativo também possuirá em suas características habilidades convergentes com alunos reativos e interessados, sendo assim, proatividade torna-se índice macro que concentra todas as características e adiciona especificações de proatividade.

O índice PRI compõe, juntamente com a nota final atribuída pelo professor no AVA Moodle, o Índice Geral apresentado na Equação 5. Este índice considera as respostasdos professores no 
survey, onde foi determinado que, notas e PRI deveriam ser utilizadas em conjunto para formar a avaliação final do aluno e o seu ranqueamento.

Consideramos um peso maior para notas em relação ao PRI, uma vez que, o índice PRI é padrão para cursos presenciais e cursos EAD e no caso de cursos presenciais a nota passa a ter um peso mais relevante visto que o PRI considera apenas interação com ambiente virtual e, no caso de cursos presenciais a proatividade, a reatividade e o interesse, podem sofrer interferências do grupo e serem manifestadas presencialmente e não refletidas no ambiente virtual. Optamos pela utilização do mesmo índice para manutenção do padrão de avaliação e para não afetar a avaliação de alunos em uma possível transição de um ambiente para o outro.

$$
\mathbf{P R I}=(\text { Proatividade } * 0,4)+(\text { Reatividade } * 0,3)+(\text { Interesse } * 0,3)
$$

$$
\text { Índice Geral }=(\operatorname{Notas} * 0,6)+(P R I * 0,4)
$$

É importante enfatizar que, no AVA Moodle não é possível atribuir menções como norteia o plano pedagógico da instituição que foi utilizada como base para este estudo e por este motivo as avaliações neste AVA possuem notas numéricas.

\section{Implementação do Software Grouprofile}

Para permitir a utilização do modelo Grouprofile, efetuou-se a programação do software Grouprofile. Este software foi implementado para monitorar o comportamento dos alunos que utilizam um AVA, neste caso o AVA Moodle. O software Grouprofile, se integra com o banco de dados onde o AVA armazena as informações, analisa estas informações classificando o grupo de aprendizes conforme as métricas definidas no modelo e apresenta estes dados ao professor.

Na construção no software Grouprofile, foi utilizada a linguagem de programação web $\mathrm{PHP}^{1}$. O banco de dados utilizado para armazenagem do histórico do contexto de cada aprendiz foi o MySQL. Para construção das telas do protótipo e aperfeiçoamento do layout, foi utilizado BootStrap ${ }^{2}$, que é um framework para desenvolvimento de $\mathrm{HTML}^{3}, \mathrm{CSS}^{4}$ e JavaScript. Este protótipo de software está disponível apenas na versão web, podendo ser acessado via dispositivo móvel apenas por navegador, futuramente pretende-se desenvolver um aplicativo para dispositivos móveis para facilitar a utilização pelo professor.

\footnotetext{
web.

${ }^{1}$ PHP: Hypertext Preprocessor - Linguagem de programação interpretada, utilizada para desenvolvimento para a

${ }^{2}$ http://getbootstrap.com.br/

${ }^{3}$ HTML (HyperText Markup Language) - linguagem de marcação utilizada na construção de páginas na Web.

${ }^{4}$ CSS (Cascading Style Sheets) Estrutura de formatação de estilo (cores, fontes, espaçamento etc) de um documento web.
} 
A Figura 6 apresenta a tela inicial do protótipo Grouprofile ${ }^{5}$, que está disponível no site de um dos autores deste trabalho, juntamente com o AVA Moodle ${ }^{6}$ utilizado neste experimento. O funcionamento do protótipo se dá pela análise dos logs gerados e armazenados no banco de dados do AVA. O resultado desta análise é armazenada do banco de dados do Grouprofile pelo Agente Registro Histórico. Esta tela contém um formulário de login, onde o docente insere as mesmas credenciais utilizadas no AVA.

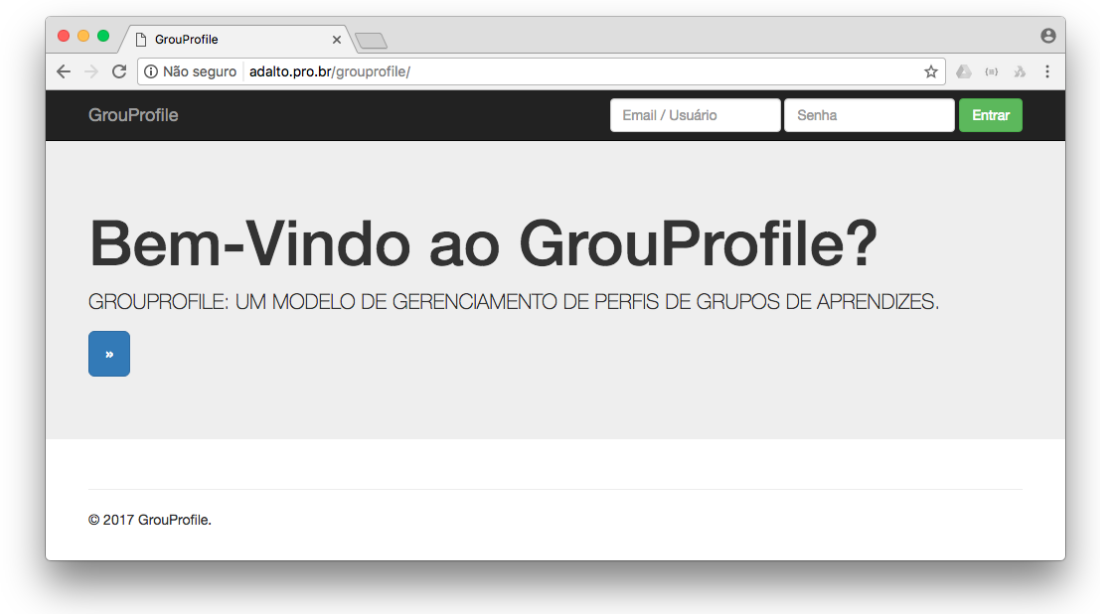

Figura 6: Tela inicial do protótipo Grouprofile.

Ao acessar, é carregada a tela onde são listados todos os cursos em que este usuário está cadastrado como professor. Esta tela está ilustrada na Figura 7. Então o docente deve escolher qual dos cursos será exibido.

A Figura 8(b) apresenta a tela com os gráficos dos indicadores de proatividade, reatividade e interesse do grupo de aprendizes. O sistema realiza a consulta dos indicadores no banco de dados do modelo Grouprofile e constrói os gráficos, através de funções JavaScript disponibilizadas pela API do Google Charts ${ }^{7}$. Esta tela apresenta também os quartis de aprendizes com melhor e pior desempenho.

Os indicadores de cada aprendiz do grupo, são apresentados na tela que está ilustrada na Figura 8(a). Nesta tela constam os indicadores de cada quesito, juntamente com os gráficos de proatividade, reatividade e interesse, onde é possível visualizar o histórico de evolução do aprendiz. Os indicadores que podem ser visualizados na Figura 8(a) são reais, de um aprendiz de um curso presencial que utilizou o AVA, somente o nome no aprendiz foi substituído nesta representação por um nome fictício.

Além das telas já ilustradas, foram também construídas no protótipo, as seguintes telas:

\footnotetext{
${ }^{5}$ Grouprofile: http://adalto.pro.br/Grouprofile

${ }^{6}$ AVA Moodle: http://adalto.pro.br/moodle

${ }^{7}$ Google Charts - Disponível em: https://developers.google.com/chart/
} 


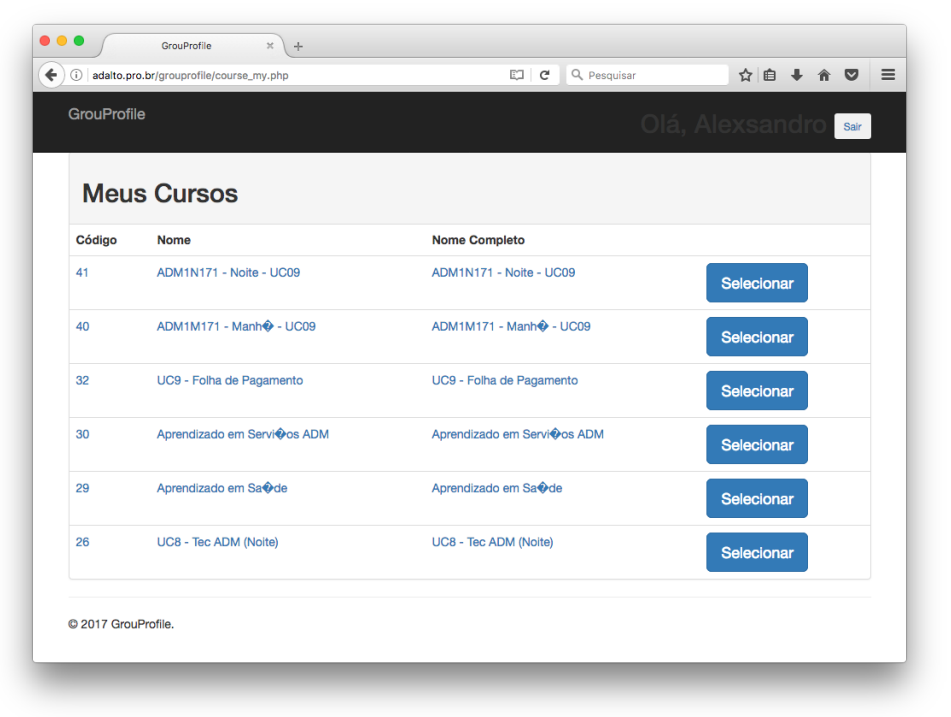

Figura 7: Tela que lista os cursos do docente.

- Lista de Aprendizes: tela que lista os aprendizes ordenados pelo alfabeto, juntamente com o total de vezes que acessaram o AVA;

- Ranking Proatividade: tela que lista os aprendizes ordenados pelo indicador de proatividade, de forma decrescente;

- Ranking Reatividade: esta tela contém a lista os aprendizes ordenados pelo indicador de reatividade, de forma decrescente;

- Ranking Interesse: esta tela permite ao usuário, visualizar a lista dos aprendizes ordenados pelo indicador de interesse, de forma decrescente;

- Configurar Curso: esta tela permite ao docente, selecionar o contexto em que o curso está inserido, se é EaD ou Presencial.

\section{Aspectos de Avaliação}

Com o propósito de avaliar a viabilidade de aplicação do modelo Grouprofile, foram adotadas duas estratégias, sendo elas uma prova de conceito por exemplo de uso e, um estudo de caso. Primeiramente foi elaborado um exemplo de uso, fazendo uso de dados que simulam um grupo de aprendizes no contexto de educação a distância e dados que simulam aprendizes no contexto presencial. Posteriormente efetuou-se um estudo de caso com um grupo de aprendizes de ensino presencial. 


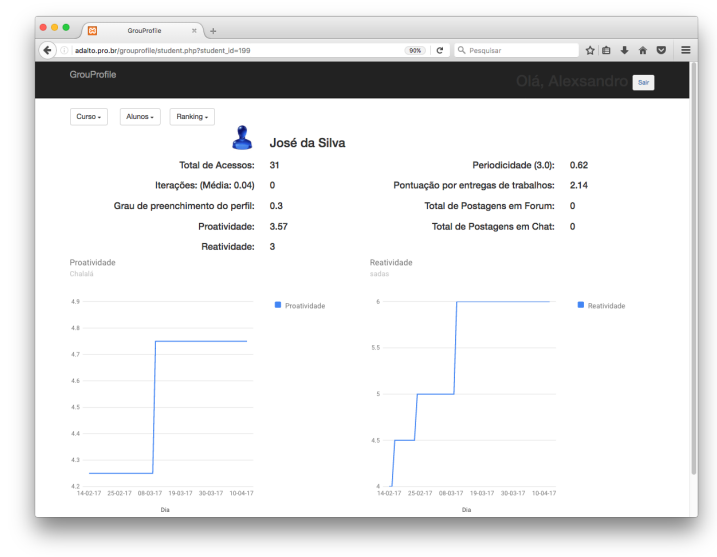

(a) Tela que apresenta os indicadores de cada aprendiz

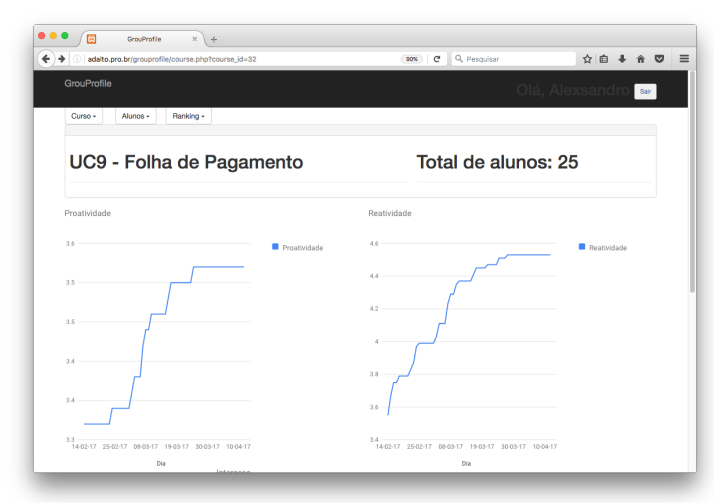

(b) Tela que apresenta os gráficos com indicadores do grupo

Para o contexto de educação a distância, não foi possível realizar estudo de caso em ambiente real, porque a instituição de ensino que permitiu acesso a base de dados do AVA, não oferta cursos na modalidade $\mathrm{EaD}$ e desta forma não foi possível obter acesso a dados reais de turmas nesta modalidade. Sendo assim, para EaD optou-se pela utilização apenas de exemplo de uso com dados simulados para a prova de conceito.

Para ambos os exemplos de uso foram utilizados dados simulados de um grupo formado por 15 aprendizes, os quais possuem as mais diversas características no que tange proatividade e reatividade. Para cada um dos critérios, elaborou-se uma tabela para representação dos cálculos que foram utilizados. A seção 7.1 apresenta o detalhamento deste estudo, sendo dividido por turmas e por critérios.

\subsection{Exemplo de uso do Modelo Grouprofile em Educação a Distância}

Nesta seção, são apresentados os dados referentes ao exemplo de aplicação do modelo Grouprofile em educação a distância.

\subsubsection{Proatividade}

Para o cálculo de proatividade em educação a distância foram avaliados os seguintes critérios: Número de interações no ambiente virtual (chat, fórum e e-mail), Número de Acessos ao ambiente virtual, Periodicidade de Acessos ao ambiente virtual, Período de Entrega de Trabalhos e Dados Cadastrais Completos. Os dados referentes a estes cálculos foram separados em duas tabelas para fins de apresentação visual, sendo elas a Tabela 1 e a Tabela 2.

Analisando as Tabelas 1 e 2, os professores teriam embasamento para identificar que o quartil de alunos com maior proatividade é composto pelos alunos "k", "m" e "j" com respectivamente 
as notas 10,9 e 8,45. Estes valores consideram um período de 30 dias, onde ocorreram as entregas de 4 trabalhos avaliativos, em que o aprendiz com maior número de interações com o ambiente virtual de aprendizagem contabilizou 60 interações e cuja média de acesso da turma ao ambiente virtual de aprendizagem foi de 12 acessos.

De posse destes dados, o professor responsável pela turma poderá tomar ações estratégicas para estimular os alunos com menor proatividade e consequentemente ajudar estes a melhorar o aproveitamento em relação aos conteúdos estudados no curso. Bem como, o professor conseguirá conhecer com base em dados concretos, os alunos mais proativos da turma, possibilitando envolvêlos em atividades específicas que possam além de beneficiá-los, auxiliar na evolução dos colegas.

\subsubsection{Reatividade}

O modelo Grouprofile prevê o cálculo de reatividade dos aprendizes, objetivando identificar o perfil de cada um e também o perfil de consenso do grupo de aprendizes, no que tange este critério. Para este fim foram considerados os seguintes aspectos: Entrega De Trabalhos No Prazo; Envio de E-mail; Número de Acessos ao Ambiente Virtual; Número de Interações no Ambiente Virtual, e; Postagem em Chat.

No cenário utilizado para este estudo, consideramos os seguintes parâmetros:

1. Média Interações: 19.

2. Maior Interação: 60.

3. Média Acessos: 10.

4. Avaliações: 4.

5. Média E-mail: 3.

6. Média Interações: 19.

7. Média Chat: 8 .

De acordo com estes critérios, constatou-se que os alunos que possuem os melhores índices de reatividade são os alunos "j", "k" e "i" com respectivamente as notas 10, 10 e 9,5. Assim como a proatividade, estes índices permitem ao professor estimular os alunos mais reativos através da proposição de novas atividades em que estes possam atuar, bem como incentivar os alunos menos reativos para que estes busquem acompanhar a turma, tornando-se mais ativos. Os valores utilizados para cálculo de reatividade segundo o modelo Grouprofile, podem ser vistos sintetizados nas Tabelas 3 e 4. 


\subsubsection{Interesse}

Para o cálculo de interesse, o modelo Grouprofile considera uma média ponderada da proatividade e da reatividade, sendo atribuído $60 \%$ do peso da avaliação para proatividade e $40 \%$ do peso da avaliação para reatividade. A Tabela 5 sintetiza os resultados de interesse, considerando os valores de proatividade e reatividade supracitados. Sendo que, os alunos "K", "O", "H" e "A" com as respectivas notas $8,53,8,51,8,47$ e 8,44, foram avaliados como os alunos mais interessados da turma.

\subsubsection{Quartis de Melhor e Pior Desempenho}

Para cálculo dos aprendizes de melhor e de pior desempenho, considerou-se os índices de proatividade, reatividade, interesse e também as notas obtidas nos trabalhos avaliativos realizados no curso. O índice PRI \{proatividade (40\%), reatividade(30\%), interesse(30\%)\} foi calculado com a seguinte média ponderada: proatividade com peso 4 , reatividade possuindo peso 3 e interesse, também contendo peso 3, totalizando 10 pontos. As notas obtidas nos trabalhos avaliativos somaram mais 10 pontos, calculados com média aritmética e a partir disso aplicado a Equação 6:

$$
\text { IndiceGeral }=(P R I * 0,4)+(N O T A S * 0,6)
$$

A Tabela 6 sintetiza estes dados, onde é possível perceber que os aprendizes que possuem o melhor índice em uma avaliação de amplo aspecto, que envolve questões de perfil (proatividade, reatividade, interesse) e questões de assimilação de conteúdos, explorada pelos trabalhos avaliativos, são os seguintes: "f" (índice 9,13), "a" (índice 8,78) e "g” (índice 8,62). Por outro lado, os aprendizes com pior desempenho do grupo, os quais merecem uma atenção especial, são os alunos “o” (índice 5,77), “c” (índice 5,72) e "n" (índice 5,57). 
Tabela 1: Proatividade: Interações, Acessos e Periodicidade de Acessos.

\begin{tabular}{|c|c|c|c|c|c|c|c|c|}
\hline & \multicolumn{2}{|c|}{$\mathrm{N}^{0}$ de interações } & \multicolumn{2}{|c|}{$\mathrm{N}^{\mathrm{o}}$ de Acessos } & \multicolumn{4}{|c|}{ Periodicidade de Acesso } \\
\hline Aluno & $\begin{array}{ll}\mathrm{N}^{0} & \mathrm{de} \\
\text { interações }\end{array}$ & Total & $\begin{array}{l}\mathrm{N}^{0} \mathrm{de} \\
\text { Acessos }\end{array}$ & Total & $\begin{array}{lr}\text { Acessos } 24 \\
\text { horas antes do } \\
\text { prazo }\end{array}$ & $\begin{array}{l}\text { Acesso } \\
\text { de forma } \\
\text { Continua }\end{array}$ & $\begin{array}{l}\text { Acessos } \text { em } \\
\text { até } 24 \text { horas } \\
\text { depois do } \\
\text { lançamento }\end{array}$ & Total \\
\hline $\mathrm{a}$ & 20 & 1 & 20 & 0,5 & 3 & 7 & 10 & 3 \\
\hline $\mathrm{b}$ & 3 & 0,15 & 10 & 0,5 & 4 & 0 & 0 & 2 \\
\hline $\mathrm{c}$ & 3 & 0,15 & 5 & 0 & 5 & & 0 & 1 \\
\hline $\mathrm{d}$ & 3 & 0,15 & 8 & 0 & 6 & 2 & 0 & 2 \\
\hline$\overline{\mathrm{e}}$ & 2 & 0,1 & 12 & 0,5 & 2 & 6 & 4 & 3 \\
\hline $\mathrm{f}$ & 15 & 0,75 & 13 & 0,5 & 2 & 6 & 5 & 3 \\
\hline $\mathrm{g}$ & 10 & 0,5 & 14 & 0,5 & 4 & 6 & 4 & 3 \\
\hline $\mathrm{h}$ & 8 & 0,4 & 7 & 0 & 2 & 4 & 3 & 3 \\
\hline $\mathrm{i}$ & 25 & 1,25 & 6 & 0 & 4 & 2 & 0 & 2 \\
\hline $\mathrm{j}$ & 33 & 1,65 & 18 & 0,5 & 6 & 4 & 8 & 3 \\
\hline $\mathrm{k}$ & 60 & 3 & 13 & 0,5 & 3 & 2 & 8 & 3 \\
\hline 1 & 18 & 0,9 & 10 & 0,5 & 2 & 4 & 4 & 3 \\
\hline $\mathrm{m}$ & 50 & 2,5 & 9 & 0 & 3 & 4 & 2 & 3 \\
\hline $\mathrm{n}$ & 14 & 0,7 & 7 & 0 & 4 & 3 & 0 & 2 \\
\hline 0 & 27 & 1,35 & 5 & 0 & 4 & 1 & 0 & 2 \\
\hline
\end{tabular}

Tabela 2: Proatividade: Entrega de Trabalhos, Cadastro Completo e Média Final.

\begin{tabular}{|c|c|c|c|c|c|c|c|c|c|c|}
\hline \multicolumn{3}{|c|}{ Entrega de Trabalhos } & & \multicolumn{6}{|c|}{ Cadastro Completo } & \multirow{2}{*}{ Média } \\
\hline $\begin{array}{l}\text { Entregas } \\
\text { nas pri- } \\
\text { meiras } \\
24 \text { horas }\end{array}$ & $\begin{array}{l}\text { Entregas } \\
\text { na pri- } \\
\text { meira } \\
\text { metade } \\
\text { do } \\
\text { prazo }\end{array}$ & $\begin{array}{l}\text { Entregas } \\
\text { na se- } \\
\text { gunda } \\
\text { metade } \\
\text { do } \\
\text { prazo }\end{array}$ & Total & Foto & Nome & Sobrenome & Telefone & Cidade & Total & \\
\hline 4 & 0 & 0 & 3 & Sim & Sim & Sim & Não & Sim & 0,4 & 7,9 \\
\hline 0 & 2 & 1 & 1,25 & Não & Sim & Sim & Não & Sim & 0,3 & 4,2 \\
\hline 0 & 1 & 2 & 1 & Não & Sim & Sim & Sim & Sim & 0,4 & 2,55 \\
\hline 0 & 0 & 3 & 0,75 & Sim & Sim & Sim & Não & Sim & 0,4 & 3,3 \\
\hline 0 & 0 & 2 & 0,5 & Não & Sim & Sim & Sim & Sim & 0,4 & 4,5 \\
\hline 2 & 2 & 0 & 2,5 & Sim & Sim & Sim & Não & Sim & 0,4 & 7,15 \\
\hline 1 & 2 & 1 & 1,75 & Sim & Sim & Sim & Não & Sim & 0,4 & 6,15 \\
\hline 2 & 2 & 0 & 2,5 & Não & Sim & Sim & Não & Sim & 0,3 & 6,2 \\
\hline 0 & 1 & 3 & 1,25 & Não & Sim & Sim & Sim & Sim & 0,4 & 4,9 \\
\hline 4 & 0 & 0 & 3 & Não & Sim & Sim & Não & Sim & 0,3 & 8,45 \\
\hline 4 & 0 & 0 & 3 & Sim & Sim & Sim & Sim & Sim & 0,5 & 10 \\
\hline 0 & 2 & 0 & 1 & Não & Sim & Sim & Não & Sim & 0,3 & 5,7 \\
\hline 1 & 3 & 0 & 3 & Sim & Sim & Sim & Sim & Sim & 0,5 & 9 \\
\hline 0 & 0 & 4 & 1 & Não & Sim & Sim & Sim & Sim & 0,4 & 4,1 \\
\hline 0 & 4 & 0 & 2 & Sim & Sim & Sim & Não & Sim & 0,4 & 5,75 \\
\hline
\end{tabular}


Tabela 3: Reatividade: Entrega De Trabalhos No Prazo, Envio de E-mail e Número de Acessos ao Ambiente Virtual .

\begin{tabular}{|c|c|c|c|c|c|c|c|c|c|c|c|}
\hline & Entregas & No & Envio de & E-mail & & & & Acessos & $\mathrm{Amb}$ & nte Virtual & \\
\hline Aprendiz & Número & Total & Número & $\begin{array}{l}\text { Maior } \\
\text { que a } \\
\text { Média }\end{array}$ & $\begin{array}{l}\text { Maior } \\
\text { que } \\
\text { me-- } \\
\text { tade da } \\
\text { média }\end{array}$ & $\begin{array}{l}\text { Menor } \\
\text { que } \\
\text { me- } \\
\text { tade da } \\
\text { média }\end{array}$ & Total & Número & $\begin{array}{l}\text { Maior } \\
\text { que a } \\
\text { média }\end{array}$ & $\begin{array}{l}\text { Maior } \\
\text { que } 0 \\
\text { e até } \\
\text { metade } \\
\text { média }\end{array}$ & Total \\
\hline $\mathrm{a}$ & 4 & 2 & 5 & SIM & - & - & 2 & 20 & Sim & - & 1 \\
\hline $\mathrm{b}$ & 3 & 1,5 & 0 & - & - & SIM & 0,5 & 10 & - & Sim & 0,5 \\
\hline $\mathrm{c}$ & 3 & 1,5 & 0 & - & - & SIM & 0,5 & 5 & Sim & - & 1 \\
\hline $\mathrm{d}$ & 3 & 1,5 & 0 & - & - & SIM & 0,5 & 8 & - & Sim & 0,5 \\
\hline $\mathrm{e}$ & 2 & 1 & 0 & - & - & SIM & 0,5 & 12 & Sim & - & 1 \\
\hline $\mathrm{f}$ & 4 & 2 & 6 & SIM & - & - & 2 & 13 & Sim & - & 1 \\
\hline $\mathrm{g}$ & 4 & 2 & 3 & SIM & - & - & 2 & 14 & Sim & - & 1 \\
\hline $\mathrm{h}$ & 4 & 2 & 2 & - & SIM & - & 1 & 7 & - & Sim & 0,5 \\
\hline i & 4 & 2 & 4 & SIM & - & - & 2 & 6 & - & Sim & 0,5 \\
\hline $\mathrm{j}$ & 4 & 2 & 10 & SIM & - & - & 2 & 18 & Sim & - & 1 \\
\hline $\mathrm{k}$ & 4 & 2 & 10 & SIM & - & - & 2 & 13 & Sim & - & 1 \\
\hline 1 & 2 & 1 & 3 & SIM & - & - & 2 & 10 & Sim & - & 1 \\
\hline $\mathrm{m}$ & 4 & 2 & 5 & SIM & - & - & 2 & 9 & - & Sim & 0,5 \\
\hline $\mathrm{n}$ & 4 & 2 & 2 & - & SIM & - & 1 & 7 & - & Sim & 0,5 \\
\hline o & 4 & 2 & 3 & SIM & - & - & 2 & 5 & - & Sim & 0,5 \\
\hline
\end{tabular}

Tabela 4: Reatividade: Número de Interações e Postagem em Chat.

\begin{tabular}{|l|l|l|l|l|l|l|l|l|l|l|}
\hline \multicolumn{9}{|c|}{ Interações } & \multicolumn{6}{c|}{ Postagem em Chat } & Média \\
\hline Número & $\begin{array}{l}\text { Acima } \\
\text { da } \\
\text { média }\end{array}$ & $\begin{array}{l}\text { Acima } \\
\text { da me- } \\
\text { tade da } \\
\text { média }\end{array}$ & $\begin{array}{l}\text { Maior } \\
\text { que zero } \\
\text { e até a } \\
\text { metade } \\
\text { da média }\end{array}$ & Total & Número & $\begin{array}{l}\text { Acima } \\
\text { da } \\
\text { média }\end{array}$ & $\begin{array}{l}\text { Acima } \\
\text { da me- } \\
\text { tade da } \\
\text { média }\end{array}$ & $\begin{array}{l}\text { Maior } \\
\text { que zero } \\
\text { eté a } \\
\text { metade } \\
\text { da média }\end{array}$ & Total & \\
\hline 20 & Sim & - & - & 3 & 3 & - & - & Sim & 0,5 & 8,5 \\
\hline 3 & - & - & Sim & 1 & 0 & - & - & - & 0 & 3,5 \\
\hline 3 & - & - & Sim & 1 & 0 & - & - & - & 0 & 4 \\
\hline 3 & - & - & Sim & 1 & 0 & - & - & - & 0 & 3,5 \\
\hline 2 & - & - & Sim & 1 & 0 & - & - & - & 0 & 3,5 \\
\hline 15 & Sim & - & - & 3 & 4 & - & Sim & - & 1 & 9 \\
\hline 10 & - & Sim & - & 2 & 0 & - & - & - & 0 & 7 \\
\hline 8 & - & - & Sim & 1 & 0 & - & - & - & 0 & 4,5 \\
\hline 25 & Sim & - & - & 3 & 10 & Sim & & - & 2 & 9,5 \\
\hline 33 & Sim & - & - & 3 & 20 & Sim & - & - & 2 & 10 \\
\hline 60 & Sim & - & - & 3 & 40 & Sim & - & - & 2 & 10 \\
\hline 18 & - & Sim & - & 2 & 5 & - & Sim & - & 1 & 7 \\
\hline 50 & Sim & - & - & 3 & 30 & Sim & - & - & 2 & 9,5 \\
\hline 14 & - & Sim & - & 2 & 3 & - & - & Sim & 0,5 & 6 \\
\hline 27 & Sim & - & - & 3 & 8 & Sim & - & - & 2 & 9,5 \\
\hline
\end{tabular}




Tabela 5: Resultados de Interesse Baseado na Proatividade e na Reativi
\begin{tabular}{|c|c|c|c|}
\hline & Proatividade & Reatividade & Interesse \\
\hline K & 7,55 & 10 & $\mathbf{8 , 5 3}$ \\
\hline O & 7,85 & 9,5 & $\mathbf{8 , 5 1}$ \\
\hline H & 7,45 & 10 & $\mathbf{8 , 4 7}$ \\
\hline A & 8,4 & 8,5 & $\mathbf{8 , 4 4}$ \\
\hline G & 7,4 & 9,5 & $\mathbf{8 , 2 4}$ \\
\hline E & 7 & 9 & $\mathbf{7 , 8}$ \\
\hline F & 6,25 & 7 & $\mathbf{6 , 5 5}$ \\
\hline N & 4,25 & 9,5 & $\mathbf{6 , 3 5}$ \\
\hline L & 5,55 & 7 & $\mathbf{6 , 1 3}$ \\
\hline M & 6,4 & 4,5 & $\mathbf{5 , 6 4}$ \\
\hline $\mathbf{C}$ & 4,9 & 6 & $\mathbf{5 , 3 4}$ \\
\hline I & 5,3 & 3,5 & $\mathbf{4 , 5 8}$ \\
\hline J & 4,75 & 3,5 & $\mathbf{4 , 2 5}$ \\
\hline B & 3,9 & 4 & $\mathbf{3 , 9 4}$ \\
\hline D & 3,9 & 3,5 & $\mathbf{3 , 7 4}$ \\
\hline
\end{tabular}

Tabela 6: Quartis de Melhor e Pior Desempenho.

\begin{tabular}{|l|l|l|l|l|l|l|}
\hline Aprendizes & Reatividade & Proatividade & Interesse & Índice PRI & Notas & $\begin{array}{l}\text { Coeficiente } \\
\text { Geral }\end{array}$ \\
\hline a & 8,5 & 8,4 & 8,53 & 8,469 & 9 & 8,7876 \\
\hline $\mathrm{b}$ & 3,5 & 4,75 & 8,51 & 5,503 & 8 & 7,0012 \\
\hline c & 4 & 3,9 & 8,47 & 5,301 & 6 & 5,7204 \\
\hline d & 3,5 & 3,9 & 8,44 & 5,142 & 7 & 6,2568 \\
\hline e & 3,5 & 5,3 & 8,24 & 5,642 & 9 & 7,6568 \\
\hline f & 9 & 7 & 7,8 & 7,84 & 10 & 9,136 \\
\hline g & 7 & 6,25 & 6,55 & 6,565 & 10 & 8,626 \\
\hline h & 4,5 & 6,4 & 6,35 & 5,815 & 7 & 6,526 \\
\hline i & 9,5 & 4,25 & 6,13 & 6,389 & 6 & 6,1556 \\
\hline j & 10 & 7,55 & 8,53 & 8,579 & 5 & 6,4316 \\
\hline k & 10 & 7,45 & 5,34 & 7,582 & 8 & 7,8328 \\
\hline l & 7 & 5,55 & 4,58 & 5,694 & 9 & 7,6776 \\
\hline m & 9,5 & 7,85 & 4,25 & 7,265 & 7 & 7,106 \\
\hline n & 6 & 4,9 & 3,94 & 4,942 & 6 & 5,5768 \\
\hline o & 9,5 & 7,4 & 3,74 & 6,932 & 5 & 5,7728 \\
\hline
\end{tabular}

\subsection{Exemplo de uso do Modelo Grouprofile em Educação Presencial}

Nesta seção apresentamos os dados referentes ao exemplo de aplicação do modelo Grouprofile em

Educação Presencial. 


\subsubsection{Proatividade Educação Presencial}

Para o cálculo de proatividade neste contexto foram avaliados os critérios: Número de interações; Número de Acessos; Cadastro Completo; Periodicidade de Acesso, e; Entrega de Trabalhos. Sobre todos estes critérios, Periodicidade de Acessos e Entrega de Trabalhos são os mais valorizados, tendo como peso 4 pontos cada um. Os dados referentes a estes cálculos são apresentados na Tabela 7 e na Tabela 8 .

Tabela 7: Proatividade Presencial: Número de interações, Números de Acessos e Cadastro Completo .

\begin{tabular}{|l|l|l|l|l|l|l|l|l|l|l|}
\hline \multicolumn{3}{|c|}{ Interações } & \multicolumn{3}{c|}{ Acessos } & \multicolumn{5}{c|}{ Cadastro Completo } \\
\hline Aluno & Número & Total & Número & Total & Foto & Nome & Sobrenome & Telefone & Cidade & Total \\
\hline a & 20 & 0,33 & 20 & 1 & Sim & Sim & Sim & Não & Sim & 0,4 \\
\hline b & 3 & 0,05 & 10 & 1 & Não & Sim & Sim & Não & Sim & 0,3 \\
\hline c & 3 & 0,05 & 5 & 0 & Não & Sim & Sim & Sim & Sim & 0,4 \\
\hline d & 3 & 0,05 & 8 & 0 & Sim & Sim & Sim & Não & Sim & 0,4 \\
\hline e & 2 & 0,03 & 12 & 1 & Não & Sim & Sim & Sim & Sim & 0,4 \\
\hline f & 15 & 0,25 & 13 & 1 & Sim & Sim & Sim & Não & Sim & 0,4 \\
\hline g & 10 & 0,16 & 14 & 1 & Sim & Sim & Sim & Não & Sim & 0,4 \\
\hline h & 8 & 0,13 & 7 & 0 & Não & Sim & Sim & Não & Sim & 0,3 \\
\hline i & 25 & 0,41 & 6 & 0 & Não & Sim & Sim & Sim & Sim & 0,4 \\
\hline j & 33 & 0,55 & 18 & 1 & Não & Sim & Sim & Não & Sim & 0,3 \\
\hline k & 60 & 1 & 13 & 1 & Sim & Sim & Sim & Sim & Sim & 0,5 \\
\hline l & 18 & 0,3 & 10 & 1 & Não & Sim & Sim & Não & Sim & 0,3 \\
\hline m & 50 & 0,83 & 9 & 0 & Sim & Sim & Sim & Sim & Sim & 0,5 \\
\hline n & 14 & 0,23 & 7 & 0 & Não & Sim & Sim & Sim & Sim & 0,4 \\
\hline o & 27 & 0,45 & 5 & 0 & Sim & Sim & Sim & Não & Sim & 0,4 \\
\hline
\end{tabular}

Tabela 8: Proatividade Presencial: Periodicidade de Acesso, Entrega de Trabalhos e Média de Proatividade.

\begin{tabular}{|l|l|l|l|l|l|l|l|l|l|}
\hline \multicolumn{2}{|l|}{ Periodicidade de Acesso } & \multicolumn{2}{l|}{ Entrega de Trabalhos } & Média \\
\hline $\begin{array}{l}24 \text { horas antes } \\
\text { do prazo }\end{array}$ & $\begin{array}{l}\text { Acessos } \\
\text { Contínuos }\end{array}$ & $\begin{array}{l}\text { Primeiras } \\
24 \text { horas }\end{array}$ & Total & $\begin{array}{l}\text { Primeiras } \\
24 \text { horas }\end{array}$ & $\begin{array}{l}1^{\mathrm{a}} \text { metade } \\
\text { do prazo }\end{array}$ & $\begin{array}{l}2^{\mathrm{a}} \text { metade } \\
\text { do prazo }\end{array}$ & $\begin{array}{l}\text { Ultimo } \\
\text { dia }\end{array}$ & Total \\
\hline 3 & 7 & 10 & 4 & 4 & 0 & 0 & 0 & 4 & 9,73 \\
\hline 4 & 0 & 0 & 1 & 0 & 2 & 1 & 0 & 2 & 4,35 \\
\hline 5 & 0 & 0 & 1 & 0 & 1 & 1 & 1 & 1,5 & 2,95 \\
\hline 6 & 2 & 0 & 3 & 0 & 0 & 2 & 1 & 1,25 & 4,7 \\
\hline 2 & 6 & 4 & 4 & 0 & 0 & 2 & 0 & 1 & 6,43 \\
\hline 2 & 6 & 5 & 4 & 2 & 2 & 0 & 0 & 3,5 & 9,15 \\
\hline 4 & 6 & 4 & 4 & 1 & 2 & 1 & 0 & 2,75 & 8,31 \\
\hline 2 & 4 & 3 & 4 & 2 & 2 & 0 & 0 & 3,5 & 7,93 \\
\hline 4 & 2 & 0 & 3 & 0 & 1 & 1 & 2 & 1,75 & 5,56 \\
\hline 6 & 4 & 8 & 4 & 4 & 0 & 0 & 0 & 4 & 9,85 \\
\hline 3 & 2 & 8 & 4 & 4 & 0 & 0 & 0 & 4 & 10,5 \\
\hline 2 & 4 & 4 & 4 & 0 & 2 & 0 & 0 & 1,5 & 7,1 \\
\hline 3 & 4 & 2 & 4 & 1 & 3 & 0 & 0 & 2,5 & 7,83 \\
\hline 4 & 3 & 0 & 3 & 0 & 0 & 2 & 2 & 1,5 & 5,13 \\
\hline 4 & 1 & 0 & 3 & 0 & 4 & 0 & 0 & 3 & 6,85 \\
\hline
\end{tabular}


Analisando as tabelas apresentadas, os professores teriam embasamento para identificar que o quartil de alunos com maior proatividade é composto pelos alunos "k", "m" e "j" com respectivamente as notas 10,5; 9,85 e 9,73. Estes valores consideram um período de 30 dias, aonde ocorreram as entregas de 4 trabalhos avaliativos, onde o aprendiz com maior número de interações com o ambiente virtual de aprendizagem contabilizou 60 interações e cuja média de acesso da turma ao ambiente virtual de aprendizagem foi de 12 acessos.

\subsubsection{Reatividade Educação Presencial}

Para o cálculo de reatividade em educação presencial foram avaliados os seguintes critérios: Entrega De Trabalhos No Prazo; Envio de E-mail; Número de Acessos ao Ambiente Virtual; Número de Comentários em Fórum, e; Postagem em Chat, Para cada um destes critérios foi atribuído um peso diferente, sendo eles: Entrega de trabalhos e atividades: 2 pontos; Envio de E-mail: 2 pontos; Número de Acessos: 1 ponto; Número de Interações: 3 pontos, e; Postagem em Chat: 2 pontos.

Os dados referentes a estes cálculos foram separados em duas tabelas para fins de apresentação visual, sendo elas a Tabela 9 e na Tabela 10.

Tabela 9: Reatividade Presencial: Entrega De Trabalhos No Prazo, Envio de E-mail e Número de Acessos ao Ambiente Virtual .

\begin{tabular}{|c|c|c|c|c|c|c|c|c|c|c|c|c|}
\hline \multicolumn{3}{|c|}{$\begin{array}{l}\text { Entrega De Traba- } \\
\text { lhos No Prazo }\end{array}$} & \multicolumn{5}{|c|}{ Envio de E-mail } & \multicolumn{5}{|c|}{ Acessos ao Ambiente Virtual } \\
\hline Aluno & Número & Total & Número & $\begin{array}{l}\text { Acima } \\
\text { da } \\
\text { Mé- } \\
\text { dia }\end{array}$ & $\begin{array}{l}\text { Maior } \\
\text { que } \\
\text { a } \\
\text { me- } \\
\text { tade } \\
\text { da } \\
\text { mé- } \\
\text { dia }\end{array}$ & $\begin{array}{l}\text { Inferior } \\
\text { a Me- } \\
\text { tade da } \\
\text { Média }\end{array}$ & Total & Número & $\begin{array}{l}\text { Superior } \\
\text { a mé- } \\
\text { dia }\end{array}$ & $\begin{array}{l}\text { Superior } \\
\text { a me- } \\
\text { tade da } \\
\text { média }\end{array}$ & $\begin{array}{l}\text { Maior } \\
\text { que } \\
\text { zero } \\
\text { até a } \\
\text { me- } \\
\text { tade da } \\
\text { média }\end{array}$ & Total \\
\hline $\mathrm{a}$ & 4 & 2 & 5 & SIM & - & - & 2 & 20 & Sim & - & - & 2 \\
\hline $\mathrm{b}$ & 3 & 1,5 & 0 & - & - & SIM & 0,5 & 10 & - & Sim & - & 1 \\
\hline $\mathrm{c}$ & 3 & 1,5 & 0 & - & - & SIM & 0,5 & 5 & Sim & - & - & 2 \\
\hline $\mathrm{d}$ & 3 & 1,5 & 0 & & - & SIM & 0,5 & 8 & - & - & Sim & 0,5 \\
\hline $\mathrm{e}$ & 2 & 1 & 0 & - & - & SIM & 0,5 & 12 & Sim & - & - & 2 \\
\hline $\mathrm{f}$ & 4 & 2 & 6 & SIM & - & - & 2 & 13 & Sim & - & - & 2 \\
\hline $\mathrm{g}$ & 4 & 2 & 3 & SIM & - & - & 2 & 14 & Sim & - & - & 2 \\
\hline $\mathrm{h}$ & 4 & 2 & 2 & - & SIM & - & 1 & 7 & - & Sim & - & 1 \\
\hline $\mathrm{i}$ & 4 & 2 & 4 & SIM & - & - & 2 & 6 & - & - & Sim & 0,5 \\
\hline $\mathrm{j}$ & 4 & 2 & 10 & SIM & - & - & 2 & & Sim & - & - & 2 \\
\hline $\mathrm{k}$ & 4 & 2 & 10 & SIM & - & - & 2 & 13 & Sim & - & - & 2 \\
\hline 1 & 2 & 1 & 3 & SIM & - & - & 2 & 10 & Sim & - & - & 2 \\
\hline $\mathrm{m}$ & 4 & 2 & 5 & SIM & - & - & 2 & 9 & - & Sim & - & 1 \\
\hline $\mathrm{n}$ & 4 & 2 & 2 & - & SIM & - & 1 & 7 & - & - & Sim & 0,5 \\
\hline o & 4 & 2 & 3 & SIM & - & - & 2 & 5 & - & Sim & - & 1 \\
\hline
\end{tabular}


Tabela 10: Reatividade Presencial: Número de comentários em fórum, Postagem em Chat e Média de Reatividade.

\begin{tabular}{|l|l|l|l|l|l|l|l|}
\hline \multicolumn{2}{|l|}{ Número de comentários em fórum } & \multicolumn{5}{|c|}{ Postagem em Chat } & \multirow{2}{*}{ Média } \\
\cline { 1 - 6 } $\begin{array}{l}\text { Acima da da } \\
\text { média }\end{array}$ & $\begin{array}{l}\text { Maior que } \\
\text { zero e até a } \\
\text { média }\end{array}$ & Total & Número & $\begin{array}{l}\text { Acima da mé- } \\
\text { dia } \\
\text { tade da média }\end{array}$ & Total & \\
\hline Sim & - & 1 & 3 & - & Sim & 0,5 & 7,5 \\
\hline- & Sim & 0,5 & 0 & - & - & 0 & 3,5 \\
\hline- & Sim & 0,5 & 0 & - & - & 0 & 4,5 \\
\hline- & - & 0 & 0 & - & - & 0 & 2,5 \\
\hline- & Sim & 0,5 & 0 & - & - & 0 & 4 \\
\hline Sim & - & 1 & 4 & - & Sim & 0,5 & 7,5 \\
\hline- & Sim & 0,5 & 0 & - & - & 0 & 6,5 \\
\hline- & - & 0 & 0 & - & - & 0 & 4 \\
\hline Sim & - & 1 & 10 & Sim & - & 1 & 6,5 \\
\hline Sim & - & 1 & 20 & Sim & - & 1 & 8 \\
\hline Sim & - & 1 & 40 & Sim & - & 1 & 8 \\
\hline- & Sim & 0,5 & 5 & - & Sim & 0,5 & 6 \\
\hline Sim & - & 1 & 30 & Sim & - & 1 & 7 \\
\hline- & Sim & 0,5 & 3 & - & Sim & 0,5 & 4,5 \\
\hline Sim & - & 1 & 8 & Sim & - & 1 & 7 \\
\hline
\end{tabular}

\subsubsection{Interesse}

Para o cálculo de interesse, o modelo Grouprofile considera os mesmos parâmetros que para educação presencial. Sendo eles uma média ponderada da proatividade e da reatividade, com a atribuição de $60 \%$ do peso da avaliação para proatividade e $40 \%$ do peso para reatividade. A Tabela 11 sintetiza os resultados de interesse considerando os valores de proatividade e reatividade supracitados. Sendo que, os alunos "k" com nota de reatividade 9,5 , o aluno "j" com nota de reatividade 9,11 e o aluno "a" com nota de reatividade 8,838 foram avaliados como os alunos mais interessados da turma.

Tabela 11: Interesse Educação Presencial.

\begin{tabular}{|l|l|l|l|}
\hline Aluno & Interesse & Aluno & Interesse \\
\hline $\mathrm{k}$ & 9,5 & $\mathrm{~h}$ & 6,358 \\
\hline $\mathrm{j}$ & 9,11 & $\mathrm{i}$ & 5,936 \\
\hline $\mathrm{a}$ & 8,838 & $\mathrm{e}$ & 5,458 \\
\hline $\mathrm{f}$ & 8,49 & $\mathrm{n}$ & 4,878 \\
\hline $\mathrm{g}$ & 7,586 & $\mathrm{~b}$ & 4,01 \\
\hline $\mathrm{m}$ & 7,498 & $\mathrm{~d}$ & 3,82 \\
\hline $\mathrm{o}$ & 6,91 & $\mathrm{c}$ & 3,57 \\
\hline $\mathrm{l}$ & 6,66 & \multicolumn{3}{|l}{} \\
\hline
\end{tabular}




\subsubsection{Quartis de Melhor e Pior Desempenho Educação Presencial}

Para cálculo dos aprendizes de melhor e de pior desempenho para educação presencial, utiliza-se os mesmo parâmetros que para educação a distância, ou seja, considera-se os índices de proatividade, reatividade, interesse e também as notas obtidas nos trabalhos avaliativos realizados no curso. A Tabela 13 sintetiza estes dados, nesta tabela pode-se perceber que os aprendizes que possuem o melhor índice em uma avaliação de amplo aspecto que envolve questões de perfil (proatividade, reatividade, interesse) e questões de assimilação de conteúdos, explorada pelos trabalhos avaliativos, são os seguintes: "c" com índice 9,19776; "d" com índice 8,9076, e; "b" com índice 8,8664. Por outro lado, os alunos com pior desempenho do grupo, os quais merecem uma atenção especial, são os alunos: "a" com índice 5,73456; "j” com índice 5,394, e; "k"com índice 5,3704 .

Tabela 12: Quartis de Melhor e Pior Desempenho.

\begin{tabular}{|l|l|l|l|l|l|}
\hline \multicolumn{6}{|c|}{ Quartil Melhor Desempenho } \\
\hline ID & Proatividade & Reatividade & Interesse & PRI & Índice Geral \\
\hline VVZ & 5,53 & 5,56 & 5,542 & 5,5426 & 8,09704 \\
\hline ONM & 5,61 & 6 & 5,766 & 5,7738 & 7,94952 \\
\hline YWK & 4,88 & 5 & 4,928 & 4,9304 & 7,61216 \\
\hline WYK & 5,48 & 6 & 5,688 & 5,6984 & 7,55936 \\
\hline TSU & 5,31 & 5 & 5,186 & 5,1798 & 7,47192 \\
\hline NHP & 4,32 & 4,67 & 4,46 & 4,467 & 7,4268 \\
\hline \multicolumn{5}{|l|}{ Quartil Pior Desempenho } \\
\hline BCA & 5,25 & 6 & 5,55 & 5,565 & 5,466 \\
\hline ZXV & 3,16 & 3 & 3,096 & 3,0928 & 4,59712 \\
\hline FED & 5,52 & 4,5 & 5,112 & 5,0916 & 2,03664 \\
\hline JIK & 4,11 & 6 & 4,866 & 4,9038 & 1,96152 \\
\hline WYK & 0,3 & 0 & 0,18 & 0,174 & 0,0696 \\
\hline STU & 0 & 0 & 0 & 0 & 0 \\
\hline
\end{tabular}

\subsection{Estudo de caso: Aplicação do modelo Grouprofile em uma Turma de Educação Pre- sencial}

Neste estudo de caso exploramos a aplicação do modelo Grouprofile para o monitoramento dos perfis dos alunos de um curso técnico em administração. Este curso aconteceu na modalidade presencial e o grupo era formado por 15 aprendizes. É importante enfatizar que neste trabalho os nomes dos alunos foram substituídos por indicadores para preservar a identidade dos aprendizes. A Tabela 13 sintetiza estes resultados, ordenando os aprendizes por índice geral.

Nesta Tabela é possível identificar o grupo de aprendizes de melhor desempenho e o grupo de aprendizes com desempenho inferior em um contexto geral, bem como identificar os índices de cada um dos alunos. Na Tabela 12 estão listados os aprendizes que integram o quartil de melhor desempenho e o quartil de desempenho inferior. 
Tabela 13: Estudo de caso: Sintetização dos Resultados.

\begin{tabular}{|l|l|l|l|l|l|}
\hline Aprendiz & Proatividade & Reatividade & Interesse & \multicolumn{1}{|c|}{ PRI } & Índice Geral \\
\hline QPP & 5,53 & 5,56 & 5,542 & 5,5426 & 8,09704 \\
\hline GHI & 5,61 & 6 & 5,766 & 5,7738 & 7,94952 \\
\hline ONM & 4,88 & 5 & 4,928 & 4,9304 & 7,61216 \\
\hline ZXV & 5,48 & 6 & 5,688 & 5,6984 & 7,55936 \\
\hline VXZ & 5,31 & 5 & 5,186 & 5,1798 & 7,47192 \\
\hline IHG & 4,32 & 4,67 & 4,46 & 4,467 & 7,4268 \\
\hline WYK & 3,88 & 5 & 4,328 & 4,3504 & 7,32016 \\
\hline TSU & 4,3 & 4,5 & 4,38 & 4,384 & 7,0336 \\
\hline PQP & 7,4 & 4,5 & 6,24 & 6,182 & 7,0328 \\
\hline DEF & 5,5 & 4,5 & 5,1 & 5,08 & 7,012 \\
\hline BCA & 4,68 & 4,5 & 4,608 & 4,6044 & 7,00176 \\
\hline NHP & 4,35 & 3 & 3,81 & 3,783 & 6,9732 \\
\hline PQR & 4,54 & 4,5 & 4,524 & 4,5232 & 6,96928 \\
\hline YWK & 4,74 & 6 & 5,244 & 5,2692 & 6,96768 \\
\hline LKJ & 4,02 & 5 & 4,412 & 4,4316 & 6,93264 \\
\hline UTS & 3,98 & 6 & 4,788 & 4,8284 & 6,91136 \\
\hline WYK & 4,37 & 4,67 & 4,49 & 4,496 & 6,8984 \\
\hline ABC & 4,69 & 4,5 & 4,614 & 4,6102 & 6,88408 \\
\hline MNO & 4,1 & 3,29 & 3,776 & 3,7598 & 5,94392 \\
\hline FED & 5,25 & 6 & 5,55 & 5,565 & 5,466 \\
\hline JKL & 3,16 & 3 & 3,096 & 3,0928 & 4,59712 \\
\hline VVZ & 5,52 & 4,5 & 5,112 & 5,0916 & 2,03664 \\
\hline JIK & 4,11 & 6 & 4,866 & 4,9038 & 1,96152 \\
\hline STU & 0,3 & 0 & 0,18 & 0,174 & 0,0696 \\
\hline OPM & 0 & 0 & 0 & 0 & 0 \\
\hline & & & & & \\
\hline
\end{tabular}

\subsection{Comparação da opinião do professor que ministrou a disciplina com os valores apon- tados pelo modelo Grouprofile}

Após a criação e implementação do modelo Grouprofile, foi aplicado um questionário para o professor do curso no qual foi aplicado este estudo. O objetivo com este questionário foi identificar se as respostas apontadas pelo monitor do modelo Grouprofile, se aproximam da opinião do professor e se estas podem auxiliar os professores a compreender melhor o processo de avaliação, utilizando estes indicadores como parte das avaliações. O professor respondeu as seguintes perguntas:

1. Na sua percepção, liste o quartil (um quarto da turma) de alunos MAIS PROATIVOS:

- Nesta pergunta três dos aprendizes listados pelo professor também foram apontados pelo modelo Grouprofile, sendo eles: "ONM", "WYK" e "BCA";

2. Na sua percepção, liste o quartil (um quarto da turma) de alunos MAIS REATIVOS: 
- Da mesma forma que na pergunta a respeito de proatividade, três dos aprendizes listados pelo professor como mais reativos, também foram apontados pelo modelo Grouprofile como mais reativos, sendo eles: "ONM", "JIK" e "UTS";

3. Na sua percepção, liste o quartil (um quarto da turma) de alunos que demonstraram ter MAIS INTERESSE:

- Da mesma forma que na pergunta a respeito de proatividade e na reatividade, três dos aprendizes listados pelo professor como mais reativos, também foram apontados pelo modelo Grouprofile como mais reativos, sendo eles: "ONM", "JIK" e "UTS";

4. Considerando os 3 itens (proatividade, reatividade e interesse), liste o quartil (um quarto do grupo) de aprendizes MAIS:

- Neste critério, os alunos listados pelo professor para compor o quartil de alunos com melhor desempenho não coincidem com os apontados pelo modelo Grouprofile.

A partir das respostas obtidas e do cruzamento destas respostas com os dados apontados pelo Grouprofile, foi possível obter algumas considerações que serão enumeradas na sequência:

1. As fórmulas utilizadas para medição de proatividade, reatividade e interesse se aproximam da percepção que o professor possui em sala de aula, sendo uma opção de suporte a estas avaliações;

2. Foi identificada uma situação específica onde três alunos foram avaliados pelo modelo Grouprofile e pelo professor como parte do quartil de melhor desempenho e ao mesmo tempo, um quarto aluno que segundo o modelo Grouprofile estaria classificado no quartil de melhor desempenho encontra-se, na visão do professor, no quartil de pior desempenho. Acredita-se que esta situação ocorre devido ao professor utilizar em suas avaliações critérios pessoais e não os indicadores relacionados ao desenvolvimento da competência, o que gerou uma discrepância no critério de avaliação entre um e outro aluno.

3. Quando somado diversos critérios para formar a avaliação de um aluno, os parâmetros podem ser perdidos pelo professor, um exemplo disso é um aluno que foi apontado do quartil de melhor desempenho para proatividade, reatividade e interesse e que não é apontado como destaque positivo na visão do professor, para a soma dos três critérios;

4. O modelo Grouprofile vai permitir a padronização e a metrificação das avaliações, reduzindo este problema e facilitando o trabalho de avaliação dos alunos. 


\section{Conclusão}

Este trabalho apresentou o desenvolvimento de um modelo e um protótipo, com o propósito de criação de agentes de software para gerenciamento de perfis de grupos de aprendizes em ambientes virtuais de aprendizagem, com ênfase em proatividade, reatividade e interesse de aprendizes destes ambientes. O protótipo foi utilizado em cursos presenciais, onde foi utilizado o AVA Moodle como ferramenta de apoio ao docente e ao corpo discente, com o propósito de confrontar as percepções do docente com as informações de perfil do grupo, gerado pelo protótipo. Estas informações do perfil do grupo são referentes a proatividade, reatividade e interesse. Com base no confronto efetuado, identificou-se que as métricas propostas permitem obter resultados que se aproximam da percepção do docente em sala de aula. Além disso, foi possível constatar que o modelo Grouprofile pode auxiliar os professores na realização das avaliações de forma imparcial e baseado em dados numéricos, uma vez que, identificou-se divergências nos critérios de avaliação aplicados para os alunos de um mesmo grupo de aprendizes. Desta forma, acredita-se que o modelo Grouprofile apresenta um avanço significativo para preencher a lacuna existente na literatura no que diz respeito a identificação de perfis de grupos e avaliação de grupos de aprendizes em ambientes virtuais de aprendizagem.

Dando sequência a este trabalho, almeja-se efetuar uma nova validação do modelo Grouprofile, porém agora, em uma turma de aprendizes no modelo EAD. Além disso, está em andamento um estudo que complementa este trabalho, através da utilização de mineração de dados afetivos para medição de proatividade, reatividade, interesse e colaboração. Neste trabalho os conceitos de proatividade, reatividade, interesse e colaboração serão avaliados a partir de recomendações de objetos de aprendizagem e a evolução do perfil do aprendiz em função destas recomendações será analisada.

\section{Agradecimentos}

Os autores agradecem à Fundação de Amparo à Pesquisa do Estado do Rio Grande do Sul (FAPERGS), ao Conselho Nacional de Desenvolvimento Científico e Tecnológico (CNPq) e à Universidade do Vale do Rio dos Sinos (Unisinos) pelo apoio ao desenvolvimento desse trabalho. O presente trabalho foi realizado com apoio da Coordenação de Aperfeiçoamento de Pessoal Nível Superior - Brasil (CAPES) - Código de Financiamento 001.

\section{Referências}

Amaral, É., Ávila, B., Zednik, H., \& Tarouco, L. (2011). Laboratório virtual de aprendizagem: uma proposta taxonômica. RENOTE. [GS Search]

Aretio, L. G., Corbella, M. R., \& Figaredo, D. D. (2007). De la educación a distancia a la 
educación virtual. Ariel. [GS Search]

Dey, A. K., Abowd, G. D., \& Salber, D. (2001). A conceptual framework and a toolkit for supporting the rapid prototyping of context-aware applications. Hum.-Comput. Interact. [GS Search]

Ferreira, L. G. A., Barbosa, J. L. V., Gluz, J. C., \& Vicari, R. (2015). Ubigroup: Um modelo de recomendação ubíqua de conteúdo para grupos dinâmicos de aprendizes. Revista Brasileira de Informática na Educação. [GS Search]

Fleury, M. T. L., \& Fleury, A. (2001). Construindo o conceito de competência. Revista de administração contemporânea, 5(SPE). [GS Search]

Horn, M. B., Staker, H., \& Christensen, C. (2015). Blended: usando a inovação disruptiva para aprimorar a educação. Penso Editora. [GS Search]

Levis, D., Barbosa, J. L. V., Pinto, S. C. S., \& Barbosa, D. (2008). Aperfeiçoamento automático do perfil do aprendiz em ambientes de educação ubíqua. Revista Brasileira de Informática na Educação. [GS Search]

Moodle (2019). Moodle. Retrieved from https://download.moodle.org

Nóbrega, A. F. d., Barbosa, J. L. V., \& Barbosa, D. N. F. (2015). Um modelo para gerenciamento de perfis de entidades através de inferência em trilhas. Unisinos. [GS Search]

Odell, J. (2010). Agent technology: an overview. Ann Arbor, MI USA, http://www. jamesodell. com. [GS Search]

Penterich, E. (2005). Ambientes virtuais de aprendizagem. Sala de Aula e Tecnologias. [GS Search]

Pereira, A. T. C., Schmitt, V., \& Dias, M. (2007). Ambientes virtuais de aprendizagem. AVAAmbientes Virtuais de Aprendizagem em Diferentes Contextos. Rio de Janeiro: Editora Ciência Moderna Ltda. [GS Search]

Primo, A. F. T. (1998). Interação mútua e interação reativa: uma proposta de estudo. In Congresso brasileiro de ciências da comunicação. [GS Search]

Russell, S., \& Norvig, P. (1995). Artificial intelligence: A modern approach. Artificial Intelligence. Prentice-Hall, Egnlewood Cliffs. [GS Search]

Schmitt, M. A. R., Tarouco, L. M. R., Okuyama, F. Y., Zielinski, F. D. C., \& Franco, M. H. I. (2015). Uma ferramenta de learning analytics para o moodle. In Nuevas ideas en informática educativa tise 2015 (Vol. 11, p. 821-824). [GS Search]

Silva, J., Rosa, J. a., Barbosa, J., Barbosa, D. N. F., \& Palazzo, L. A. M. (2009). Content distribution in trial-aware environments. In Proceedings of the xv brazilian symposium on multimedia and the web (pp. 15:1-15:8). ACM. [GS Search]

Sparremberger, A. S., Barbosa, J., \& Gluz, J. (2017). Grouprofile: Um modelo de gerenciamento de perfis de grupos de aprendizes. In Brazilian symposium on computers in education (simpósio brasileiro de informática na educação-sbie) (Vol. 28, p. 1687). [GS Search]

Wagner, A., Barbosa, J. L. V., \& Barbosa, D. N. F. (2014). A model for profile management applied to ubiquitous learning environments. Expert Systems with Applications. [GS Search]

Weiand, A., et al. (2016). Análise visual para monitoramento de alunos de cursos à distância. [GS Search] 
Wooldridge, M. (2009). An introduction to multiagent systems. John Wiley \& Sons. [GS Search] 